Published in final edited form as:

Sci Transl Med. 2016 December 07; 8(368): 368ra173. doi:10.1126/scitranslmed.aah6571.

\title{
Five-coordinate $\mathrm{H64Q}$ neuroglobin as a ligand-trap antidote for carbon monoxide poisoning
}

\author{
Ivan Azarov ${ }^{1, \dagger}$, Ling Wang ${ }^{1,2, \dagger}$, Jason J. Rose ${ }^{1,2, \dagger}$, Qinzi Xu ${ }^{1}$, Xueyin N. Huang ${ }^{1}$, Andrea \\ Belanger ${ }^{5}$, Ying Wang ${ }^{2}$, Lanping Guo ${ }^{2}$, Chen Liu ${ }^{5}$, Kamil B. Ucer ${ }^{5}$, Charles F. McTiernan ${ }^{1,2}$, \\ Christopher P. O’DonnelI ${ }^{1,2}$, Sruti Shiva ${ }^{1,3,4}$, Jesús Tejero ${ }^{1,2}$, Daniel B. Kim-Shapiro ${ }^{5,6}$, and \\ Mark T. Gladwin ${ }^{1,2,{ }^{*}}$ \\ ${ }^{1}$ Pittsburgh Heart, Lung, Blood and Vascular Medicine Institute, University of Pittsburgh, \\ Pittsburgh, Pennsylvania, USA 15261 \\ ${ }^{2}$ Division of Pulmonary, Allergy and Critical Care Medicine, UPMC and University of Pittsburgh, \\ Pittsburgh, Pennsylvania, USA 15261 \\ ${ }^{3}$ Department of Pharmacology and Chemical Biology, University of Pittsburgh, Pittsburgh, \\ Pennsylvania, USA 15261 \\ ${ }^{4}$ Center for Metabolism and Mitochondrial Medicine (C3M), University of Pittsburgh, Pittsburgh, \\ Pennsylvania, USA 15261 \\ ${ }^{5}$ Department of Physics, Wake Forest University, Winston-Salem, North Carolina, USA 27109 \\ ${ }^{6}$ Translational Science Center Wake Forest University, Winston-Salem, North Carolina, USA \\ 27109
}

\begin{abstract}
Carbon monoxide $(\mathrm{CO})$ is a leading cause of poisoning deaths worldwide, with no available antidotal therapy. We introduce a potential treatment paradigm for $\mathrm{CO}$ poisoning, based on nearirreversible binding of $\mathrm{CO}$ by an engineered human neuroglobin $(\mathrm{Ngb})$. $\mathrm{Ngb}$ is a six-coordinate hemoprotein, with the heme iron coordinated by two histidine residues. We mutated the distal histidine to glutamine (H64Q) and substituted three surface cysteines with less reactive amino acids to form a five-coordinate heme protein (Ngb-H64Q-CCC). This molecule exhibited an
\end{abstract}

*Corresponding author. gladwinmt@upmc.edu.

$\dagger$ These authors contributed equally to this work.

Author contributions: M.T.G. conceived and supervised the project. I.A. designed and performed most in vitro experiments and some in vivo experiments. L.W. designed and performed most in vivo experiments. J.J.R. and S.S. designed and performed some in vitro experiments. Q.X. performed the ventilated animal experiments. J.T. designed the H64Q-CCC modified neuroglobin, aided in expression and production and conducted some in vitro experiments. X.N.Y. performed the protein expression and purification. Y.W. and L.G. conducted animal surgery. C.P.O. and C.F.M. assisted with experimental design and critical review of the manuscript. A.B., C.L., and K.B.U. conducted laser photolysis and time resolved absorption experiments. D.B.K-S. designed and supervised laser photolysis and time resolved absorption experiments. All authors wrote and edited parts of the manuscript, read and approved the final manuscript.

Competing interests: M.T.G. and J.T. have submitted a provisional patent filing on the use of recombinant neuroglobin mutants for carbon monoxide poisoning. The other authors declare that they have no competing interests. Data and Materials Availability: Raw data and materials are available from the authors for noncommercial researchers via a materials transfer agreement.

SUPPLEMENTARY MATERIALS

Methods

References: (68-71) 
unusually high affinity for gaseous ligands, with a $\mathrm{P}_{50}$ value for oxygen of $0.015 \mathrm{mmHg}$. NgbH64Q-CCC bound CO about 500 times more strongly than did hemoglobin. Incubation of NgbH64Q-CCC with 100\% CO-saturated hemoglobin, either cell-free or encapsulated in human red blood cells, reduced the half-life of carboxy-hemoglobin to 0.11 and 0.41 minutes, respectively, from a value that is $\geq 200$ minutes when the hemoglobin or cells are only exposed to air. Infusions of Ngb-H64Q-CCC to CO-poisoned mice enhanced CO removal from red blood cells, restored heart rate and blood pressure, increased survival, and were followed by rapid renal elimination of CO-bound Ngb-H64Q-CCC. Heme-based scavenger molecules with very high CO binding affinity such as our mutant five-coordinate $\mathrm{Ngb}$ are potential antidotes for $\mathrm{CO}$ poisoning by virtue of their ability to bind and eliminate $\mathrm{CO}$.

\section{INTRODUCTION}

Carbon monoxide (CO) poisoning results in an estimated 50,000 emergency department visits in the United States annually and is one of the leading causes of poisoning death globally (1). Despite the fact that it has been appreciated since the $19^{\text {th }}$ century that CO produces tissue hypoxia by binding avidly to hemoglobin $(\mathrm{Hb})(2,3)$, to date there is no approved specific antidotal therapy. Beyond the provision of supplemental normobaric and hyperbaric oxygen, treatment has not changed significantly over the last several decades $(1$, 4). Patients with severe $\mathrm{CO}$ poisoning exhibit lactic acidosis, hemodynamic instability, and respiratory failure, which often limit their access to hyperbaric therapy. Although hyperbaric oxygen therapy reduces neurological impairment resulting from $\mathrm{CO}$ poisoning, substantive deficits usually remain $(1,5,6)$. New and effective approaches are urgently needed to treat CO poisoning (7).

Neuroglobin $(\mathrm{Ngb})$ is a cellular hemoprotein expressed in brain and retina that protects cells from death after ischemia and reperfusion injury (8-10). Mechanisms proposed for this cytoprotective effect include the reduction of cytochrome $\mathrm{c}$ or the reduction of nitrite to form nitric oxide (NO) (11-13). Unlike five-coordinate globins such as $\mathrm{Hb}$ and myoglobin (Mb), wild type Ngb has a distal histidine residue (H64) that binds to the heme iron, resulting in a six-coordinate heme (14). This bis-histidine structure is common to cytochromes and other globins (cytoglobin (15), plant Hbs (16), drosophila $\mathrm{Hb}$ (17)). In an effort to understand the mechanisms that regulate nitrite and other ligand binding to $\mathrm{Ngb}$, we generated H64 mutants that are constitutively five-coordinate (free iron ligand position similar to $\mathrm{Hb}$ and $\mathrm{Mb}$ ) (Fig. 1A) $(12,18)$. These five-coordinate mutant $\mathrm{Ngb}$ molecules can reduce nitrite to form $\mathrm{NO}$ about 2,500 times faster than $\mathrm{Hb}(12,18)$, bind oxygen with very high affinity $\left(\mathrm{P}_{50} \approx 0.015\right.$ $\mathrm{mmHg}$, Fig. S1) and show even higher affinities for CO $(14,19)$.

The essential properties of a $\mathrm{CO}$ scavenger, particularly under aerobic conditions, are: (i) high $\mathrm{CO}$ association rate $\left(k_{\mathrm{on}}\right)$ and equilibrium association constants $\left(K_{\mathrm{A}}\right)$, relative to $\mathrm{Hb}$; (ii) high $\mathrm{M}$-value $\left(K_{\mathrm{A}} \mathrm{CO} / K_{\mathrm{A}} \mathrm{O}_{2}\right)$ to allow $\mathrm{CO}$ scavenging in oxygenated blood; and (iii) a low rate of autoxidation ( $k_{\text {autox }}$ ) to allow maintenance of the reduced ferrous state, required for ligand binding. An oxygen-bound hemoprotein with a high M-value has the added advantage of releasing an oxygen molecule while binding $\mathrm{CO}$. We propose that mutant five- 
coordinate $\mathrm{Ngb}$ could satisfy these requirements and serve as a $\mathrm{CO}$ scavenger for the treatment of $\mathrm{CO}$ poisoning by binding and eliminating $\mathrm{CO}$.

\section{RESULTS}

\section{$\mathrm{H} 64$ substituted $\mathrm{Ngb}$ exhibits a higher $\mathrm{CO}$ binding affinity than $\mathrm{Hb}$}

Previous studies have identified proteins with notably high affinities for CO. For example, the $\mathrm{Hb}$ from Glycera dibranchiata has a very high association constant for $\mathrm{CO}\left(K_{\mathrm{A}}=6.4 \times\right.$ $\left.10^{8} \mathrm{M}^{-1}\right)(20)$ when compared to the value for sperm whale $\mathrm{Mb}\left(K_{\mathrm{A}}=2.7 \times 10^{7} \mathrm{M}^{-1}\right.$; Table S1) (21). In Glycera dibranchiata Hb, the distal histidine residue is replaced by a leucine; the introduction of the same replacement in $\mathrm{Mb}$ substantially increases the affinity for $\mathrm{CO}\left(K_{\mathrm{A}}=\right.$ $\left.1.1 \times 10^{8} \mathrm{M}^{-1}\right)(21)$. However, these high $\mathrm{CO}$ affinities are still below the value of the high affinity R-state $\mathrm{Hb}\left(K_{\mathrm{A}}=6.0 \times 10^{8} \mathrm{M}^{-1}\right)(22)$, suggesting that they would not scavenge $\mathrm{CO}$ effectively from CO-saturated hemoglobin. Our group has studied the effects of a similar substitution of the distal histidine of $\mathrm{Ngb}$ on nitrite reduction and other heme properties (12, 18). During the purification of these Ngb His64 mutants, we and others have detected the presence of $\mathrm{NO}$ (or CO) bound-Ngb $(18,23)$. This observation, together with the high $\mathrm{CO}$ binding rates of wild type and H64L neuroglobins $(14,19)$, suggested that distal histidine mutants of Ngb might have very high affinities towards $\mathrm{CO}$ and could function as COscavenging molecules. Such a molecule has the potential to bind oxygen and $\mathrm{CO}$, and if the $\mathrm{CO}$ affinity is higher than oxygen affinity (a high M-value), the molecule would scavenge $\mathrm{CO}$ and release oxygen. As previous studies indicate that H64Q Ngb shows a lower autoxidation rate than most $\mathrm{Ngb}$ mutants and could more stably bind oxygen (18), we focused on this mutant as a possible $\mathrm{CO}$-scavenging molecule.

We measured $\mathrm{CO}$ binding affinities in recombinant $\mathrm{Ngb}$ molecules and $\mathrm{Hb}$ at room temperature $\left(22^{\circ} \mathrm{C}\right)$ using laser flash photolysis to assess on-rates and NO displacement of $\mathrm{CO}$ for analysis of off-rates (Fig. 1B). Two Ngb mutants were evaluated: H64Q (Ngb-H64Q) and H64Q combined with three surface thiol substitutions (C46G/C55S/C120S; Ngb-H64Q$\mathrm{CCC})$ to increase protein solubility and limit oligomerization at high protein concentrations. The flash photolysis methodology allows for full release of $\mathrm{CO}$ from the heme and fast measurement of $\mathrm{CO}$ rebinding. To analyze the species formed during the reaction, we used standard reference spectra. Static absorption spectra, normalized by concentration to produce millimolar extinction coefficients, are shown for deoxy- and CO-Ngb-H64Q-CCC in Fig. 1C. The difference between these two spectra is shown in Fig. 1D. To measure CO association rate constants, the CO-bound globins were photolysed with a $20 \mathrm{~mJ}, 6 \mathrm{~ns} \mathrm{Nd}$ YAG laser pulse at $532 \mathrm{~nm}$, and the recombination kinetics were recorded for $1200 \mu \mathrm{s}$ and $100 \mu$ s for $\mathrm{Hb}$ and $\mathrm{Ngbs}$, respectively. The absorption difference spectra were calculated as the absorbance at a time $t$ minus the absorption prior to photolysis. Upon photolysis, the absorption difference spectrum is expected to be similar to that shown in Fig. 1D (deoxy minus CO-bound). As CO rebinds, the difference spectrum is expected to go to zero as the final state becomes identical to the initial $\mathrm{CO}-\mathrm{Ngb}$ state. The resulting absorption difference spectra were fit to first order kinetics by using global analysis with SpecFit software (24). The two forms of Ngb (Ngb-H64Q and Ngb-H64Q-CCC) had similar association rate constants for $\mathrm{CO}$, which were much faster than $\mathrm{Hb}$. Fig. 1E shows initial and final 
absorption difference spectra of $\mathrm{Hb} 1200 \mu$ s after the $20 \mathrm{~mJ}$ laser pulse and of $\mathrm{Ngb} 100 \mu \mathrm{s}$ after the pulse, reflecting the time it takes to rebind $\mathrm{CO}$ after flash photolysis. Note that the $\mathrm{Hb}$ reaction with $\mathrm{CO}$ is still incomplete after $1000 \mu \mathrm{s}$, with $\mathrm{Hb}$ not yet $100 \%$ bound by $\mathrm{CO}$ (Fig. 1E, F). The absorbance difference changes for the $440 \mathrm{~nm}$ peak illustrate the difference in association rates; the time decay and first order fit of the absorbance difference are shown in Fig. $1 \mathrm{~F}$ on a logarithmic scale. We monitored the binding around $440 \mathrm{~nm}$ because as the spectral changes are more pronounced and the sensitivity of the measurements is better at this wavelength, allowing the use of less protein and a laser pulse of minimal energy (but that still produced a measurable photolysis yield). Both $\mathrm{Ngb}$ molecules bound $\mathrm{CO}$ faster than did $\mathrm{Hb}$ with calculated bimolecular association rate constants of $1.3 \pm 0.4 \times 10^{8} \mathrm{M}^{-1} \mathrm{~s}^{-1}$ and $1.6 \pm 0.4 \times 10^{8} \mathrm{M}^{-1} \mathrm{~S}^{-1}$ for Ngb-H64Q and Ngb-H64Q-CCC, respectively, and $5.0 \pm 1.4$ $\times 10^{6} \mathrm{M}^{-1} \mathrm{~s}^{-1}$ for $\mathrm{Hb}$.

To determine the dissociation rates of $\mathrm{CO}$ from the Ngb mutants, the kinetics of $\mathrm{CO}$ displacement by $\mathrm{NO}$ were followed spectroscopically after mixing CO-bound globins with a solution containing a high concentration of NO. As NO is present in large excess (1 mM NO vs. $10 \mu \mathrm{M} \mathrm{CO}$ ) and binds to Ngb with very high affinity (14), released CO molecules are quickly replaced by NO (25). Samples of $10 \mu \mathrm{M}$ CO-bound protein containing $100 \mu \mathrm{M}$ sodium dithionite were mixed with $1 \mathrm{mM} \mathrm{NO}$ and immediately scanned. Absorption spectra were recorded for 45 minutes for $\mathrm{Hb}$ and 270 minutes for $\mathrm{Ngb}$ (Fig. 1G and $\mathrm{H}$ ). As the spectral changes for the two mutant Ngb molecules are similar, only Ngb-H64Q-CCC is shown. The measured dissociation rate constants were $5.2 \pm 1.4 \times 10^{-4} \mathrm{~s}^{-1}$ and $4.2 \pm 1.8 \times$ $10^{-4} \mathrm{~s}^{-1}$ for Ngb-H64Q and Ngb-H64Q-CCC, respectively, and $6.5 \pm 2.0 \times 10^{-3} \mathrm{~s}^{-1}$ for $\mathrm{Hb}$. The overall measured affinities $\left(K_{\mathrm{A}}=\mathrm{k}_{\mathrm{on}} / \mathrm{k}_{\text {off }}\right.$ values shown in Fig. 1I) were $7.95 \times 10^{8} \mathrm{M}^{-1}$ for $\mathrm{Hb}$ compared with $2.54 \pm 1.13 \times 10^{11} \mathrm{M}^{-1}$ and $3.80 \pm 0.96 \times 10^{11} \mathrm{M}^{-1}$ for Ngb-H64Q and Ngb-H64Q-CCC, respectively. When compared to our determined values for $\mathrm{Hb}, \mathrm{Ngb}-$ H64Q and Ngb-H64Q-CCC exhibited 319- and 478-fold greater affinities for CO, respectively (Fig. 1I).

Because oxygen and $\mathrm{CO}$ are both present in blood, a $\mathrm{CO}$ scavenger molecule must have a high M-value $\left(\mathrm{K}_{\mathrm{A}} \mathrm{CO} / \mathrm{K}_{\mathrm{A}} \mathrm{O}_{2}\right)$ to be able to scavenge $\mathrm{CO}$ in competition with blood oxygen. An oxygenated hemoprotein with a high $\mathrm{M}$-value would also release oxygen as it binds $\mathrm{CO}$. To determine the relative affinity of Ngb-H64Q-CCC towards oxygen, we determined the association and dissociation rates for the reaction of Ngb-H64Q-CCC and oxygen. CO-NgbH64Q-CCC $(20 \mu \mathrm{M})$ in buffer containing $100 \mu \mathrm{M} \mathrm{CO}$ and $225 \mu \mathrm{M}$ oxygen was photolyzed and the replacement by oxygen was monitored for $30 \mu$ after photolysis. The absorption difference spectra (transient - ground state) were calculated and fit by using single value decomposition and global analysis to a single exponential decay (similar approach as described above for $\mathrm{CO}$ rebinding). The observed rate constant for these data obtained from the fit was $0.12 \mu \mathrm{s}^{-1}$. The bimolecular rate constant for oxygen binding was $7.2 \pm 1.5 \times 10^{8}$ $\mathrm{M}^{-1} \mathrm{~S}^{-1}$ (Fig. S2).

In order to determine the dissociation rate of oxygen from Ngb-H64Q-CCC, we used the CO replacement method (see Methods). In short, freshly prepared oxy-Ngb complex (to avoid substantial presence of met-Ngb) was mixed with different concentrations of $\mathrm{CO}$ and the rate of decay of the oxy- $\mathrm{Ngb}$ complex (identical to the rate of formation of the $\mathrm{CO}-\mathrm{Ngb}$ 
complex) was measured. The observed rates increase hyperbolically as the $[\mathrm{CO}] /\left[\mathrm{O}_{2}\right]$ ratio increases, with the oxygen dissociation rate being the limiting rate as $[\mathrm{CO}] /\left[\mathrm{O}_{2}\right]$ becomes larger. We determined a rate for the reaction of $18.4 \pm 0.7 \mathrm{~s}^{-1}$ (Fig. S2).

The measured oxygen association and dissociation rates indicate that the oxygen equilibrium association constant $\left(K_{\mathrm{A}}=k_{\mathrm{on}} / k_{\text {off }}\right)$ is $3.9 \times 10^{7} \mathrm{M}^{-1}$, lower than the $\mathrm{CO}$ association constant $\left(3.8 \times 10^{11} \mathrm{M}^{-1}\right)$. The $\mathrm{M}$ value is $9.7 \times 10^{3}$, suggesting that Ngb-H64Q-CCC would preferentially bind $\mathrm{CO}$ in the presence of mixtures of $\mathrm{CO}$ and oxygen.

To further characterize the properties of Ngb-H64Q-CCC, we determined the autoxidation and nitrite reduction rates of the mutant at $37^{\circ} \mathrm{C}$, as described in Supplementary Materials. We observed autoxidation rates of $0.86 \pm 0.33 \mathrm{~h}^{-1}$ (Fig. S3) similar to the reported value for the Ngb-H64Q mutant $\left(0.60 \pm 0.12 \mathrm{~h}^{-1}\right)(18)$. The nitrite reduction rate constant was 320 $\pm 10 \mathrm{M}^{-1} \mathrm{~S}^{-1}$ (Fig. S4), also in agreement with the rate for the Ngb-H64Q mutant (390 \pm 20 $\mathrm{M}^{-1} \mathrm{~s}^{-1}$ ) (18); both rates were 2,500 times faster than those for human hemoglobin A (Tstate values $(12,26))$. We also performed $\mathrm{CO}$ flash photolysis binding studies at lower $\mathrm{CO}$ concentrations to exclude potential artifacts of geminate recombination, as described in the Methods section of Supplementary Materials.

Compared to other heme-containing molecules, the Ngb-H64Q mutation confers the highest $\mathrm{CO}$ affinity (Table 1), three orders of magnitude higher than Hb. The Ngb-H64Q-CCC mutant also has a high $\mathrm{M}$ value. Finally, the autoxidation rate of Ngb-H64Q-CCC is slower than that of other hemoproteins with high CO affinity, supporting the ability of Ngb-H64Q$\mathrm{CCC}$ to work as a rapid $\mathrm{CO}$ scavenger in vivo.

\section{In vitro rapid $\mathrm{CO}$ transfer from carboxy-hemoglobin to $\mathrm{Ngb}-\mathrm{H} 64 \mathrm{Q}-\mathrm{CCC}$}

We next evaluated the $\mathrm{CO}$ transfer from carboxy- $\mathrm{Hb}(\mathrm{CO}-\mathrm{Hb})$ to $\mathrm{Ngb}-\mathrm{H} 64 \mathrm{Q}-\mathrm{CCC}$ at $37^{\circ} \mathrm{C}$ under anaerobic (Fig. 2A-C) and aerobic (Fig. 2D-F) conditions (21\% $\left.\mathrm{O}_{2}, 1 \mathrm{~atm}\right)$. Under anaerobic conditions, $100 \% \mathrm{CO}-\mathrm{Hb}$ was rapidly mixed with equimolar solutions of deoxy $\mathrm{Ngb}-\mathrm{H} 64 \mathrm{Q}-\mathrm{CCC}$. We calculated the half-lives of $\mathrm{CO}$ dissociation from free $\mathrm{Hb}$ in the presence of Ngb-H64Q-CCC via single exponential fits. The experiments with free Hb were performed by using rapid manual mixing (time $<5 \mathrm{~s}$ ) in a Cary spectrophotometer. Spectral deconvolution of time-resolved absorption data collected at $37^{\circ} \mathrm{C}$ was accomplished by a least squares fit with reference spectra (Fig. S5) to determine the percentage of: CO-Ngb, $\mathrm{CO}-\mathrm{Hb}$, deoxy-Ngb, deoxy-Hb, oxy-Ngb and oxy-Hb (12, 27-30). Fig. 2A shows the absorbance spectra of $\mathrm{CO}-\mathrm{Hb}$ and deoxy-Ngb-H64Q-CCC before mixing and Fig. 2B shows absorbance spectra measured every $2.4 \mathrm{~s}$ after the two proteins were mixed under anaerobic conditions. As shown in Fig. 2C, after mixing, $\mathrm{CO}$ rapidly transferred from $\mathrm{Hb}$ to NgbH64Q-CCC, and the reaction was completed in approximately 30s. Fig. 2D-F shows similar experiments under aerobic conditions. Consistent with the measured higher affinity of NgbH64Q-CCC for CO compared with oxygen, there was minimal difference between the rates of $\mathrm{CO}$ transfer under anaerobic and aerobic conditions, with an average half-life $(\mathrm{n}=7)$ of $6.4 \pm 1.8 \mathrm{~s}$ based on single exponential fits.

We compared the dissociation rate of $\mathrm{CO}-\mathrm{Hb}$ in the presence of excess Ngb-H64Q-CCC under anaerobic conditions to the dissociation rate of $\mathrm{CO}-\mathrm{Hb}$ in the presence of $1 \mathrm{mM} \mathrm{NO}$ at 
$22{ }^{\circ} \mathrm{C}$. The $\mathrm{CO}$ dissociation rate constants with Ngb-H64Q-CCC were 2.4 times faster than the rates measured in presence of excess NO $\left(0.014 \pm 0.005 \mathrm{~s}^{-1}\right.$ vs. $\left.0.0065 \pm 0.002 \mathrm{~s}^{-1}\right)$ (Fig. S6). This difference may result from the fact that during $\mathrm{Hb}-\mathrm{CO}$ dissociation measured by $\mathrm{NO}$ displacement $\mathrm{Hb}$ is in the $\mathrm{R}$ state throughout the reaction, because binding of both $\mathrm{CO}$ and $\mathrm{NO}$ to $\mathrm{Hb}$ stabilizes the R-state. When $\mathrm{CO}$ dissociates from $\mathrm{Hb}$ in the presence of NgbH64Q-CCC, the $\mathrm{Hb}$ is initially in the R state and then transitions to the deoxygenated T-state as the $\mathrm{CO}$ is released from $\mathrm{Hb}$. As the $\mathrm{CO}$ dissociation rate for $\mathrm{T}$-state $\mathrm{Hb}$ is about 10 times faster than for the R-state (Table 1), Ngb-H64Q-CCC can scavenge CO from CO-Hb faster than the dissociation of $\mathrm{CO}$ from $\mathrm{R}$-state $\mathrm{Hb}$ in the presence of $\mathrm{NO}$.

\section{Rapid CO transfer from $100 \%$ CO saturated RBCs to extracellular Ngb-H64Q-CCC}

We next tested how fast $\mathrm{CO}$ transfers from free $\mathrm{Hb}$ to Ngb-H64Q-CCC across cellular compartments, from the red blood cell (RBC) to extracellular Ngb. To evaluate this we prepared $100 \% \mathrm{CO}$-saturated $\mathrm{RBCs}$ and incubated them at $37{ }^{\circ} \mathrm{C}$ with different ratios of extracellular Ngb-H64Q-CCC to intracellular CO-Hb under anaerobic (Fig. 3A-D) and aerobic (Fig. 3E, F) conditions. After mixing, we determined the values at frequent time points by centrifuging samples in $<5 \mathrm{~s}$ to separate erythrocytes from $\mathrm{Ngb}$ and measured $\mathrm{CO}$ bound to the intracellular $\mathrm{Hb}$ and to the supernatant Ngb-H64Q-CCC. The changes in absorbance spectra of $\mathrm{Hb}$ and $\mathrm{Ngb}-\mathrm{H} 64 \mathrm{Q}-\mathrm{CCC}$ from a representative anaerobic experiment at $37{ }^{\circ} \mathrm{C}$ are shown in Fig. 3A and Fig. 3B, respectively. The $\mathrm{Hb}$ spectra changed from $100 \%$ $\mathrm{CO}-\mathrm{Hb}$ to deoxy-Hb within 2 minutes, while the Ngb-H64Q-CCC spectra showed a complementary change of $100 \%$ deoxy-Ngb to CO-Ngb at the same time. Fig. 3C-F show example kinetics of the decrease in $\mathrm{CO}-\mathrm{Hb}$ and increase in $\mathrm{CO}-\mathrm{Ngb}-\mathrm{H} 64 \mathrm{Q}-\mathrm{CCC}$ at different stoichiometric ratios of $\mathrm{Ngb}$ to $\mathrm{Hb}$ under anaerobic and aerobic conditions. The $\mathrm{CO}-\mathrm{Hb}$ decay was fitted to a single exponential equation. The average rate constants for the reaction were $1.69 \pm 0.21 \mathrm{~min}^{-1}\left(0.028 \pm 0.004 \mathrm{~s}^{-1}\right)$ for combined anaerobic and aerobic experiments $(\mathrm{CO}-\mathrm{Hb}$ half-life $=0.41 \mathrm{~min}) ; 1.92 \pm 0.31 \mathrm{~min}^{-1}$ for anaerobic only; $1.25 \pm 0.12 \mathrm{~min}^{-1}$ for aerobic only. When atmospheric oxygen was present (Fig. 3E, F), we observed a reduction in the magnitude of $\mathrm{CO}$ transfer from $\mathrm{Hb}$ to $\mathrm{Ngb}$, although we did not see a statistically significant difference in the rate of $\mathrm{CO}$ removal from $\mathrm{CO}-\mathrm{Hb}$ compared to that in the absence of oxygen. The decrease in the total amount of $\mathrm{CO}$ scavenged is likely due to the partial oxidation of the oxy-Ngb-H64Q-CCC to form the met-Ngb-H64Q-CCC species, which cannot bind $\mathrm{CO}$. The analysis of all experiments, including those with free, unencapsulated $\mathrm{Hb}$, indicated a 1:1 stoichiometric transfer of $\mathrm{CO}$ from $\mathrm{Hb}$ to Ngb-H64QCCC under both aerobic and anaerobic conditions (Fig. 3G).

The lack of an effect of oxygen on the rates of $\mathrm{CO}$ scavenging seems counterintuitive, as Ngb-H64Q-CCC has a high association rate constant for oxygen (Table 1). To further investigate these results, we used a mathematical approximation to the observed rates at halfreaction for equimolar initial amounts of $\mathrm{CO}-\mathrm{Hb}$ and $\mathrm{Ngb}$. The observed rates of $\mathrm{CO}$ scavenging in the absence (Equation 1) or the presence of oxygen (Equation 2) can be described as: 


$$
\begin{gathered}
\mathrm{r}_{\mathrm{obs}, 50 \%} \approx \frac{k_{\mathrm{off} \mathrm{CO}, \mathrm{Hb}}}{1+\frac{k_{\text {on } \mathrm{CO}, \mathrm{Hb}}}{k_{\mathrm{on} \mathrm{CO}, \mathrm{Ngb}}}} \quad \text { (Equation 1) } \\
\mathrm{r}_{\mathrm{obs}, 50 \%} \approx \frac{k_{\text {off CO, } \mathrm{Hb}}}{1+\frac{k_{\text {on } \mathrm{CO}, \mathrm{Hb}} \times \mathrm{P}_{50, \mathrm{HbO}_{2}}}{k_{\text {on } \mathrm{CO}, \mathrm{Ngb}} \times \mathrm{P}_{50, \mathrm{NgbO}_{2}}}} \quad \text { (Equation }
\end{gathered}
$$

Where $k_{\text {on }}$ and $k_{\text {off }}$ denote the binding and dissociation rates for the ligands and proteins indicated. The $\mathrm{P}_{50}$ values can be approximated by the dissociation rates divided by the

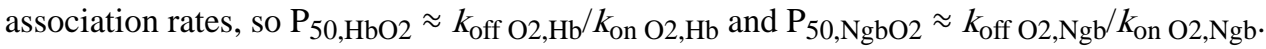
A detailed derivation of these expressions is provided in the Methods section of Supplementary Materials.

Substituting the experimental values (Table 1) into equations 1 and 2 , we find that the high

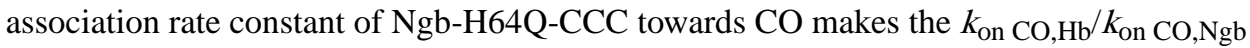
term small, and thus the calculated observed rates correspond to $\mathrm{r}_{\mathrm{Obs}} \approx 0.96 \times k_{\mathrm{Off}} \mathrm{CO}$, $\mathrm{Hb}$ in anaerobic conditions. However, in aerobic conditions the affinity towards oxygen is higher for Ngb-H64Q-CCC than for Hb, and this partly offsets the CO-dependent portion of the term, with $\left(k_{\mathrm{O} \text { CO, } \mathrm{Hb}} \times \mathrm{P}_{50, \mathrm{HbO} 2}\right) /\left(k_{\mathrm{On} \mathrm{CO}, \mathrm{Ngb}} \times \mathrm{P}_{50, \mathrm{NgbO} 2}\right)=0.43$ and thus $\mathrm{r}_{\text {obs }} \approx 0.70 \times$ $k_{\text {off } \mathrm{CO}, \mathrm{Hb}}$. This small effect of oxygen on the observed rates is in very good agreement with our experimental data. Computer simulations using the experimental rate constants (see Supplementary Materials for details) suggest even smaller differences, with $\mathrm{r}_{\mathrm{obs}} \approx 1.04 \times$ $k_{\mathrm{Off}} \mathrm{CO}, \mathrm{Hb}$ in anaerobic conditions and $\mathrm{r}_{\mathrm{obs}} \approx 0.90 \times k_{\mathrm{off}} \mathrm{CO}, \mathrm{Hb}$ in aerobic conditions. These results can be understood by observing that the effect of oxygen in decreasing the amount of deoxyNgb available for $\mathrm{CO}$ scavenging is offset by the decrease in deoxyHb, which can rebind free $\mathrm{CO}$ and slow the reaction.

To better characterize the CO removal efficacy of Ngb-H64Q-CCC, wild type Ngb, apoNgb, albumin (BSA), and oxidized Ngb (met-Ngb) were tested as additional controls. Wild type $\mathrm{Ngb}$ incubated with $\mathrm{CO}$-saturated $\mathrm{RBCs}$ bound $\mathrm{CO}$ at a significant slower rate $\left(\mathrm{k}_{\mathrm{obs}}=0.61\right.$ $\pm 0.15 \mathrm{~min}^{-1}$; $\mathrm{CO}-\mathrm{Hb}$ half-life $1.3 \mathrm{~min}$ ) than did the mutant five-coordinate molecule, while other molecules did not bind $\mathrm{CO}$ at all and did not affect $\mathrm{CO}$ removal from $\mathrm{CO}$-saturated RBCs (Fig. 3H). Half-lives of CO dissociation from RBC-encapsulated or free Hb from mouse and humans are summarized in Fig. 3I. When only atmospheric oxygen was available to displace $\mathrm{CO}$ from the $\mathrm{Hb}$ in human $\mathrm{RBCs}$, the observed $\mathrm{CO}-\mathrm{Hb}$ half-life was $>500$ minutes, while in the presence of Ngb-H64Q-CCC, with and without atmospheric oxygen, it was reduced to only 0.41 minutes $(25 \mathrm{~s}$ ) (Fig. 3I). The CO-Hb half-life was about 0.11 minutes (7s) with mixtures of free $\mathrm{CO}-\mathrm{Hb}$ and $\mathrm{Ngb}-\mathrm{H} 64 \mathrm{Q}-\mathrm{CCC}$. The difference in $\mathrm{CO}$ scavenging rates by Ngb-H64Q-CCC from RBC vs. free $\mathrm{Hb}$ (0.41 vs. 0.11 min half-life) yielded a quantitative estimation for the effect of the diffusion barrier to $\mathrm{CO}$ movement out of the cells, a result of slow diffusion in the highly viscous red cell cytoplasm and unstirred 
layers external to the cell. In both cases, the rates in the presence of Ngb-H64Q-CCC were orders of magnitude faster than the corresponding rates in the absence of a scavenging agent.

In the presence of air, $\mathrm{CO}$ dissociation from purified free $\mathrm{Hb}$ (222 minutes half-life) was more than twice as fast as the release from RBC-encapsulated $\mathrm{Hb}$ (> 500 minutes half-life), indicating the very slow $\mathrm{CO}$ release in more physiological conditions. (Fig. 3I).

\section{$\mathrm{Ngb}-\mathrm{H} 64 \mathrm{Q}-\mathrm{CCC}$ rapidly removes $\mathrm{CO}$ from $\mathrm{Hb}$ in a non-lethal, $\mathrm{CO}$ poisoning mouse model}

To test whether Ngb-H64Q-CCC can effectively remove CO in vivo, we exposed mice to 1,500 ppm CO gas mixed with air (Fig. 4), which steadily increased systemic CO-Hb levels, plateauing at $64 \pm 1 \%$ ( $n=13$, PBS- \& Ngb-infused mice combined) after 50 minutes of CO exposure. No animals died with this concentration and duration of $\mathrm{CO}$ exposure. We then stopped CO exposure and infused $250 \mu \mathrm{L}$ of $9-12 \mathrm{mM} \mathrm{Ngb-H64Q-CCC} \mathrm{(either} \mathrm{deoxy} \mathrm{or}$ partially oxy, see Table S1) or a similar volume of PBS over 4 minutes. Immediately after the infusion and every 5 minutes, $5 \mu \mathrm{l}$ of blood was collected and the RBCs were rapidly washed and lysed for the measurement of CO-Hb. In contrast to PBS, the Ngb-H64Q-CCC rapidly cleared $\mathrm{CO}$ from $\mathrm{RBCs}$ in vivo (Fig. 4A), and $\mathrm{CO}$ clearance was associated with increases in arterial blood pressure (Fig. 4B). Fig. 4C, D show representative absorbance spectra of $\mathrm{Hb}$ from the blood of a CO-poisoned mouse that received an infusion of PBS (Fig. 4C) and from a mouse that received an infusion of Ngb-H64Q-CCC (Fig. 4D). The first absorbance spectrum shown $(0 \mathrm{~min})$ was taken at the time when $\mathrm{CO}$-exposure was stopped and the animals were returned to normal atmospheric conditions. These spectra indicate 58\% and 57\% CO-Hb, respectively, for the mice with PBS and Ngb-H64Q-CCC infusions. The subsequent spectra for both animals were recorded every $5 \mathrm{~min}$ for $30 \mathrm{~min}$, followed by spectra at two 10-min intervals. The mouse receiving Ngb-H64Q-CCC had a much lower $\mathrm{CO}-\mathrm{Hb} \%$ after the first 5 minutes than the mouse that received PBS (Fig. 4C, D). Five minutes after return to normal atmospheric conditions, which is at least $30 \mathrm{~s}$ after the end of infusions, the $\mathrm{CO}-\mathrm{Hb}$ levels dropped by an average of $35.0 \pm 2.1 \%$ in the group that received Ngb-H64Q-CCC $(n=6)$ but only $13.3 \pm 0.6 \%$ in the group that received PBS $(n=7)$ (Fig. $4 \mathrm{E})$. The decrease in blood pressure during $\mathrm{CO}$ exposure was similarly low in the two groups (Fig. 4B) and consistent with severe hemodynamic instability during $\mathrm{CO}$ poisoning. At the end of the exposure, blood pressure in mice that received Ngb-H64Q-CCC was restored to near its pre-exposure values in contrast to the lower blood pressures of animals that received PBS $(P=0.0006$ for time $>0$, using a mixed effect model with unstructured covariance, Fig. 4B). This effect may be partly a result of rapid $\mathrm{CO}$ clearance, although a contribution from NO scavenging by Ngb-H64Q-CCC due to the high initial amounts of the oxy Ngb-H64Q-CCC cannot be excluded. Sixty minutes after infusion, we unexpectedly detected high concentrations of $\mathrm{Ngb}(86-94 \% \mathrm{CO}-\mathrm{Ngb})$ in the bladder, indicating the rapid removal of $\mathrm{CO}$ by Ngb-H64Q-CCC and rapid clearance of CO-Ngb-H64Q-CCC from blood to urine (Fig. 4F). In these studies, we evaluated Ngb-H64Q-CCC preparations with varying levels of oxygen saturation. There was no relationship between oxygenation status of infused $\mathrm{Ngb}-\mathrm{H} 64 \mathrm{Q}-\mathrm{CCC}$ and the extent and rate of CO-Hb clearance (Table S1), consistent with our in vitro findings and computational models (Fig. 2, 3). 
To compare the efficacy of Ngb-H64Q-CCC with $100 \%$ normobaric oxygen, widely used as a standard treatment for $\mathrm{CO}$ poisoning, mice were exposed to $100 \%$ normobaric oxygen after $\mathrm{CO}$ exposure. $\mathrm{CO}-\mathrm{Hb}$ levels dropped after the first $5 \mathrm{~min}$ by an average of $35.0 \pm 2.1 \%$ in the group that received Ngb-H64Q-CCC and by $27.4 \pm 1.6 \%$ in the group that received $100 \%$ oxygen inhalation $(\mathrm{n}=5)(P<0.05)$ (Fig. 4E), suggesting Ngb-H64Q-CCC is more potent in $\mathrm{CO}$ removal from mouse $\mathrm{RBCs}$ than is normobaric oxygen. Note that $\mathrm{CO}$ elimination in mice under normoxia and $100 \%$ oxygen is over 20 times faster than $\mathrm{CO}$ elimination in humans, while the removal rates with exposure to Ngb-H64Q-CCC differ only by 3-fold between mouse and human RBCs (Fig. 3I). This suggests that Ngb-H64Q$\mathrm{CCC}$ will be a much more effective treatment for $\mathrm{CO}$ poisoning than is oxygen therapy in humans.

\section{$\mathrm{Ngb}-\mathrm{H} 64 \mathrm{Q}-\mathrm{CCC}$ restores blood pressure, improves tissue oxygen delivery and increases survival in a lethal $\mathrm{CO}$ poisoned mouse model}

We developed a lethal, CO poisoning mouse model to test whether Ngb-H64Q-CCC increases survival after $\mathrm{CO}$ exposure compared with controlled infusions of PBS. To stabilize respiration during $\mathrm{CO}$ exposure and allow for the direct evaluation of cardiovascular collapse, the most common clinical presentation of severely poisoned patients $(4,7)$, the exposures were performed in mice on continuous mandatory ventilation with $21 \%$ oxygen. After stabilization, mice were exposed to $3 \% \mathrm{CO}$ and $21 \%$ oxygen, balanced with nitrogen, for 4.5 minutes, followed by ventilation with room air (21\% oxygen, $79 \%$ nitrogen), and the Ngb-H64Q-CCC preparation or same volume of PBS or albumin controls were infused for 2 minutes (Fig. 5A). In these experiments, the concentration of Ngb-H64Q$\mathrm{CCC}$ was $11.6 \pm 0.6 \mathrm{mM}$ with the met-Ngb form maintained at only $4.09 \pm 1.55 \%$ by adding sub-stoichiometric sodium dithionite. Ngb-H64Q-CCC was delivered as $125.4 \pm 7.2 \mathrm{nmol} / \mathrm{g}$ mouse weight in an infusion volume of $10 \mu \mathrm{l} / \mathrm{g}$ mouse weight. After infusions, the heart rate (HR) in the control mice started to drop 3 minutes after the start of CO poisoning from 269.2 \pm 44.6 to $143.9 \pm 49.2$ beats per minute (BPM). The HR continued to drop in control treated mice, while it started to increase in less than 1 minute after Ngb-H64Q-CCC infusion (Fig. $5 \mathrm{~B}, \mathrm{C})$. The MAP dropped and continued to decrease to unmeasurable values in the control groups, while MAP increased to the pre-poisoning baseline after Ngb-H64Q-CCC treatment (Fig. 5B, C). Only $10 \%$ of the mice survived in the PBS group $(\mathrm{n}=10)$ and none survived in the albumin group $(n=7)$, with median survival times of 24.5 and 23 minutes, respectively. In the Ngb-H64Q-CCC treated group, $87.5 \%$ mice $(\mathrm{n}=8)$ survived to the pre-specified protocol sacrifice time of 40 minutes (Fig. 5D; $P=0.0008$ ).

$\mathrm{CO}-\mathrm{Hb}$ levels in the blood were measured before and after the infusions in separate experiments with different mice. There was a greater drop in $\mathrm{CO}-\mathrm{Hb}$ after infusion in the Ngb-H64Q-CCC treated group than in either control group $33 \pm 0.49 \%$ in Ngb-H64Q-CCC vs. $4.66 \pm 1.05 \%$ in PBS vs. $11.08 \pm 0.96 \%$ in albumin, $P<0.0001$, Fig. $5 \mathrm{E})$, suggesting that Ngb-H64Q-CCC increased the rate of $\mathrm{CO}$ removal from $\mathrm{Hb}$ and restored the oxygen binding capacity of $\mathrm{Hb}$, which may have contributed to the improved survival. We also measured CO-Ngb in plasma at the same time points. 
Blood Ngb was almost fully saturated with $\mathrm{CO}$ immediate after the infusion $(99.87 \pm 0.20 \%$ $\mathrm{CO}-\mathrm{Ngb}$ measured in plasma), with a Ngb-H64Q-CCC concentration of $1.17 \pm 0.06 \mathrm{mM}$ in the mouse plasma. The concentration of Ngb-H64Q-CCC in plasma decayed from 1170 $\pm 60 \mu \mathrm{M}$ at the end of the infusion to $271 \pm 32 \mu \mathrm{M}$ at the end of experiment (Fig. S7). A fit of the decay of the Ngb-H64Q-CCC concentration in plasma to a single exponential equation yielded an observed rate of $0.053 \pm 0.022 \mathrm{~min}^{--1}$, corresponding to an estimated plasma half-life of $13.1 \mathrm{~min}$ (Fig. S7), consistent with the rapid renal excretion of the CObound molecule.

To understand the effects of Ngb-H64Q-CCC on tissue oxygen delivery (31) in CO poisoning, lactate measurements were performed serially after infusion of treatment and control animals (Ngb-H64Q-CCC, PBS or albumin). The infusion of Ngb-H64Q-CCC significantly lowered lactate levels in mice at both 24.5 and 40 minutes after exposure: (24.5 min: $5.77 \pm 0.86 \mathrm{mM} ; 40 \mathrm{~min}: 9.17 \pm 0.44 \mathrm{mM})$ vs. PBS ( $24.5 \mathrm{~min}: 10.67 \pm 1.53 \mathrm{mM} ; 40$ min: $14.07 \pm 0.33 \mathrm{mM}$; time $P<0.0001$; treatment $P=0.0461$; interaction $P=0.0022)$ and albumin (24.5 min: $9.6 \pm 0.20 \mathrm{mM}$; $40 \mathrm{~min}: 13.0 \pm 0.32 \mathrm{mM}$; time $P<0.0001$; treatment $P=$ 0.0376 ; interaction $P<0.0001$ ) (Fig. 5F). These findings have potential clinical relevance because low $\mathrm{pH}$ from lactic acidosis is prognostic of poor outcome in patients with severe CO poisoning (1).

\section{Toxicological assessment of Ngb-H64Q-CCC in a mouse 48-hour survival model}

In our study, CO-Ngb-H64Q-CCC was rapidly cleared from blood to urine, indicating that the kidney filters the protein, similar to the process of $\mathrm{Mb}$ clearance after rhabdomyolysis (32). To evaluate the potential toxic effects of this Ngb mutant protein in vivo, we performed an in vivo toxicological study in mice exposed to $4,000 \mathrm{ppm} \mathrm{CO}$ for 15 minutes, an exposure level that increases mouse blood $\mathrm{CO}-\mathrm{Hb}$ levels to approximately $67 \pm 5.2 \%$ of total $\mathrm{Hb}$ and is not lethal. For these survival studies, the drug was delivered by retro-orbital injection of $250 \mu \mathrm{l}$ of 9-10 mM Ngb-H64Q-CCC, and mice were sacrificed $48 \mathrm{~h}$ later for collection and analysis of blood, kidney, liver, heart, brain and lung. The retro-orbital route of delivery was used to limit surgical vascular manipulation for this study. All mice that received NgbH64Q-CCC $(n=4)$ or PBS only ( $n=4)$ were alive $48 \mathrm{~h}$ after the experiment. Complete blood counts (CBC) and blood chemistry (including creatinine, AST/ALT) for Ngb-H64Q-CCCtreated mice revealed normal values, suggesting that Ngb-H64Q-CCC does not impair renal or liver function in mice (Fig. S8). Furthermore, kidney histology was normal, and Western blot analysis did not detect $\mathrm{Ngb}$ in liver, kidney, heart, brain and lung tissues. As a positive control, we also tested $10 \mathrm{mM}$ met-Ngb-H64Q-CCC and found that this oxidized molecule that cannot bind $\mathrm{CO}$ is entrapped in the organs and produces organ injury (Fig. S8).

\section{DISCUSSION}

In the present studies, we characterized the biophysical properties of a mutant fivecoordinate neuroglobin, Ngb-H64Q-CCC. This molecule exhibited a very high CO association rate $\left(k_{\mathrm{on}}\right)$ and equilibrium association constant $\left(K_{\mathrm{A}}\right)$ relative to $\mathrm{Hb}$; it also had a high M-value $\left(K_{\mathrm{A}} \mathrm{CO} / K_{\mathrm{A}} \mathrm{O}_{2}\right)$, but relatively low autoxidation rates. These properties promoted rapid $\mathrm{CO}$ scavenging from $\mathrm{Hb}$ and $\mathrm{RBCs}$ in vitro, and in $\mathrm{CO}$-poisoned mice 
increased $\mathrm{CO}$ elimination rates and improved hemodynamics, lactic acid levels and survival. Thus, a high-affinity globin variant can successfully scavenge $\mathrm{CO}$ in vivo in mice. That such a variant may prove useful to treat $\mathrm{CO}$ poisoning in humans is supported by reports of a naturally occurring hemoglobinopathy, hemoglobin Zürich, in which the CO affinity of the mutant $\mathrm{Hb}$ Zürich is approximately 65 times greater than that of normal $\mathrm{Hb}$. Like our mutant $\mathrm{Ngb}$, this variant also carries a mutation of the distal histidine of the Hb beta chain (H63R) (33).

Rapid confirmation of $\mathrm{CO}$ poisoning and continuous monitoring of $\mathrm{CO}-\mathrm{Hb}$, which can now be performed non-invasively in the field with pulse $\mathrm{CO}$ oximetry, allows for triage and transfer of poisoned patients to facilities with hyperbaric oxygen "dive chambers". Exposure of patients to $100 \%$ normobaric or hyperbaric oxygen, the only current therapeutic options, reduces the elimination half-life of human $\mathrm{CO}-\mathrm{Hb}$ from 320 minutes to 74 and 20 minutes, respectively $(1,7,34-36)$. However, in practice the efficacy of hyperbaric oxygen therapy is often limited because of time delays between diagnosis, transportation to a hyperbaric center, and treatment $(1,6,7,37-40)$. Moreover, the most unstable patients usually require mechanical ventilation and intensive care support, which are not easily administered within a hyperbaric capsule. Even with effective hyperbaric therapy, a significant portion of patients who survive $\mathrm{CO}$ poisoning suffer from long term neurologic deficits. Neurocognitive sequelae persist in $13-37 \%$ of patients for up to 6 years after initial poisoning $(38,41)$.

Recombinant Ngb-H64Q-CCC may be rapidly administered as an antidote to CO poisoning in the field or in the emergency room, with calculated and measured clearance half-lives of less than a minute from $\mathrm{RBC} \mathrm{Hb}$. Placement of an intravenous angiocatheter and delivery of recombinant Ngb-H64Q-CCC would be anticipated to immediately decrease the $\mathrm{CO}-\mathrm{Hb}$ levels by $\approx 7-10 \%$ for every $1 \mathrm{~g} / \mathrm{dL}$ administered. Although our studies evaluated efficacy and safety only in mice, similar amounts of $\mathrm{Hb}$-based blood substitutes have been used in Phase 1 clinical trials in trauma and surgical patients (50-100 g), suggesting potential feasibility for this dosing in humans (42-44).

Other approaches for treating CO poisoning are in the early stages of development (7). These include phototherapy with light exposure to increase the rate of $\mathrm{CO}$ release from hemoglobin (45), hydroxocobalamine to metabolize CO to carbon dioxide (46), and a synthesized water-soluble supramolecular complex (hemoCD) which, when infused in rats, scavenged $\mathrm{CO}$ from the rat body and the CO-bound hemoCD was immediately excreted in the urine (47).

What causes the lethal effects of $\mathrm{CO}$ ? The formation of $\mathrm{CO}-\mathrm{Hb}$ and an associated decrease in oxygen transport originally was considered to be the major mechanism of $\mathrm{CO}$ toxicity (2, 3). However, the clinical severity in CO-poisoned patients does not directly correlate with blood $\mathrm{CO}-\mathrm{Hb}$ levels $(5,37)$, and clinical improvement does not correlate with the rate of clearance of blood $\mathrm{CO}-\mathrm{Hb}$. Also, as observed in canine studies, the toxicity of a particular concentration of $\mathrm{CO}$ is greater when $\mathrm{CO}$ is administered by inhalation rather than by transfusion of CO-exposed RBCs (48). These studies suggest that CO-Hb levels serve as a crude measure of $\mathrm{CO}$ exposure, but the lethal effects result from the global impact of both reduction in $\mathrm{Hb}$ oxygen delivery and the direct inhibition of mitochondrial respiration in 
tissues. It is now well appreciated that $\mathrm{CO}$ poisoning causes tissue ischemia-reperfusion injury, mitochondrial dysfunction and damage, cellular necrosis and apoptosis and downstream activation of immunological and inflammatory events. $\mathrm{CO}$ inhibits mitochondrial respiration by binding the ferrous heme of cytochrome $c$ oxidase (Complex IV), effectively shutting down oxidative phosphorylation, similar to the effects of cyanide (48-50). Thus removal of $\mathrm{CO}$ from the circulation is important as it will limit the continuous delivery of $\mathrm{CO}$ to the tissues, but removal of $\mathrm{CO}$ from the mitochondria is also required to further diminish $\mathrm{CO}$ toxicity. Our observations of rapid improvements in heart rate, blood pressure and lactate levels upon administration of Ngb-H64Q-CCC indicate a therapeutic effect of $\mathrm{CO}$ scavenging, consistent with reductions in blood $\mathrm{CO}$ levels and improved oxygen delivery and utilization in affected organs.

Major complications of acellular Hb-based blood substitutes used as oxygen delivery molecules, which have been tested in humans, were hypertension and multi-organ injury caused by both NO scavenging and heme-mediated oxidative reactions (51-54). There are, however, factors that may limit these complications for Ngb-H64Q-CCC treatment of CO poisoning. First, the concentration of $\mathrm{CO}-\mathrm{Hb}$ in these patients will be higher than the concentration of infused Ngb-H64Q-CCC and several orders of magnitude higher than the endogenous NO concentration. CO levels of $>30 \% \mathrm{CO}-\mathrm{Hb}$ in our studies are greater than 2 $\mathrm{mM}$, while $\mathrm{NO}$ concentrations in vivo are orders of magnitude lower (55). Thus $\mathrm{CO}$ is expected to outcompete NO for binding to the infused Ngb-H64Q-CCC, limiting NOmediated responses. Second, in the presence of CO, Ngb-H64Q-CCC binds $\mathrm{CO}$ almost irreversibly. Upon CO removal, Ngb-H64Q-CCC will be mostly CO-bound, thus blocking possible NO dioxygenation reactions, Fenton reactions, and lipid-peroxidase reactions that scavenge $\mathrm{NO}$ and generate reactive oxygen species. As revealed by our $48 \mathrm{~h}$ survival and safety study (Fig. S7), all mice with moderately severe CO poisoning that received deoxy$\mathrm{Ngb}-\mathrm{H} 64 \mathrm{Q}-\mathrm{CCC}$ injection remained alive with normal renal and liver function, while the mice given met-Ngb-H64Q-CCC (which lacks CO binding capacity) exhibited trapped metNgb-H64Q-CCC in the kidney, and showed abnormal liver and kidney function (Fig. S8). Third, Ngb-H64Q-CCC has a nitrite reductase rate constant $\approx 2,500$ times faster than that of $\mathrm{Hb}$ (Fig. S4), suggesting that the molecule may generate NO from plasma nitrite and potentially offset effects of NO scavenging $(12,18)$. Blood pressure in mice receiving NgbH64Q-CCC was restored to nearly pre-exposure levels as compared with mice that were infused with PBS, while no hypertension was observed. Moreover, hemodynamic improvements in response to Ngb-H64-CCC infusion compared to PBS were observed in the lethal poisoning model (Fig. 5B, C), without seeing increases in blood pressures above baseline values, indicating no true hypertensive effects.

There are a number of limitations inherent to our studies in mice. We measured CO clearance, hemodynamics and mortality, but have not tested long term effects on neurocognitive dysfunction, one of the major complications in humans with $\mathrm{CO}$ poisoning. We have also assessed cellular metabolism using a surrogate marker, lactic acid, rather than direct measurement of mitochondrial respiration. Further safety and efficacy studies in large animal models are needed to advance this therapy toward treatment of $\mathrm{CO}$ poisoning in humans. 
In conclusion, the current studies support the development of recombinant $\mathrm{Ngb}$ as a biological therapeutic. Despite recognition of the role of $\mathrm{Ngb}$ in cellular cytoprotection, this molecule has not previously been harnessed as a therapeutic. In addition to $\mathrm{CO}$ scavenging and oxygen delivery, Ngb may have other useful effects on cellular function via cytochrome c reduction or nitrite reduction to form $\mathrm{NO}(11-13,18)$. The triple cysteine substitutions to the H64Q Ngb reduce intramolecular cross-linking and increase protein solubility, allowing for the preparation of stable $>12 \mathrm{mM}$ stock solutions. High concentrations of $\mathrm{Ngb}$ could allow for "unit" infusions of saline containing $50-100 \mathrm{~g}$ of Ngb in the field by paramedics, necessary to increase the plasma levels to $1-2 \mathrm{~g} / \mathrm{dL}$ and stoichiometrically scavenge $\mathrm{CO}$ from $\mathrm{CO}-\mathrm{Hb}$ complexes (56), which would reduce the $\mathrm{CO}-\mathrm{Hb}$ level by an absolute percentage of approximately $10-15 \%$ (e.g. from $30 \% \mathrm{CO}-\mathrm{Hb}$ to $15-20 \%$ ). Our studies identify a potential antidotal therapy for $\mathrm{CO}$ poisoning that, if proven safe in large mammals and humans, could be given in the field by paramedics to rapidly scavenge $\mathrm{CO}$ from RBCs, tissues, and heart within minutes, providing a potential life-saving approach to the most common human poisoning.

\section{MATERIALS AND METHODS}

\section{Study design}

The objective of this study was to investigate the ability of a mutant five-coordinate Ngb mutant with very high $\mathrm{CO}$ binding affinity to serve as a $\mathrm{CO}$ scavenger for the treatment of $\mathrm{CO}$ poisoning. We characterized the $\mathrm{CO}$ and oxygen binding affinity of the mutant $\mathrm{Ngb}$ and monitored the rates of $\mathrm{CO}$ transfer from free $\mathrm{Hb}$ and $\mathrm{RBCs}$ to the mutant $\mathrm{Ngb}$ in vitro. We developed non-lethal and lethal $\mathrm{CO}$ poisoning mouse models to monitor the effect of $\mathrm{Ngb}$ mutant infusions on $\mathrm{CO}$ clearance, hemodynamics and survival rate. All the in vitro experiments were repeated at least three times. All animal studies were performed using protocols approved by the Institutional Animal Care and Use Committee at the University of Pittsburgh and in accordance with National Institutes of Health guidelines. Randomization of animals into the study was based on body weight to ensure equal distribution across groups. No statistical method was used to predetermine sample size for all experiments. Investigators were not blinded to experiments. All data are included (no outlier values were excluded).

\section{Reagents and standard sample preparation}

Blood was used freshly or up to 4 weeks after collecting from human volunteers and $\mathrm{Hb}$ was prepared as described previously(53). Mouse blood was collected from C57BL/6 mice and used within 10 days. All chemicals were purchased from Sigma unless otherwise noted. All concentrations of pre-mixed $\mathrm{CO}$ gas were purchased from Matheson Inc. and were confirmed by Testo combustion analyzer 320 in our lab. Visible absorbance spectra and kinetic data were collected on a Cary 50 and a HP8453 UV-visible spectrophotometer (Agilent Technologies). All experiments were performed in PBS, (Sigma). CO-saturated buffer was prepared by bubbling $10-20 \mathrm{~mL}$ of PBS with CO gas for at least 30 minutes. Stock sodium dithionite solution was prepared by adding PBS degassed by Argon flowthrough to a degassed vial of dry sodium dithionite. 


\section{Neuroglobin expression and purification}

Site-directed mutagenesis of the wild type Ngb to H64Q and H64Q combined with three surface thiol substitutions (a C46G, C55S, and C120S mutation), referred to as Ngb-H64Q and Ngb-H64Q-CCC, respectively, was performed using QuikChange II kit (Stratagene), as described previously $(12,14)$ For expression, cDNA was cloned in the E. coli competent cells Rosetta 2(DE3) or BL21 (DE3) from Novagen, with the Ngb-H64Q-CCC gene carried by pET-28 plasmid (Novagen). A $25 \%$ glycerol stock of the cells was stored at $-80{ }^{\circ} \mathrm{C}$. Expression of cells grown in $\mathrm{LB}$ broth at $37{ }^{\circ} \mathrm{C}$ was induced upon reaching $\mathrm{OD}_{600}$ of 0.9 with $1 \mathrm{mM}$ isopropyl 1 -thio- $\beta$-D-galactopyranoside and included $\delta$-aminolevulinic acid $(0.4$ $\mathrm{mM}$ ) in the media. Expression of cells grown in autoinducing media (57) was induced upon reaching $\mathrm{OD}_{600}$ of 0.45 by switching incubation temperature from 37 to $18{ }^{\circ} \mathrm{C} .30 \mu \mathrm{g} / \mathrm{ml}$ Kanamycin was added to media containing either BL21 or Rosetta cells while $34 \mu \mathrm{g} / \mathrm{ml}$ Chloramphenicol was added only to the Rosetta cells. For cells in autoinducing media, the incubation temperature was raised from 18 to $30^{\circ} \mathrm{C}$ the next day (after $\sim 20 \mathrm{~h}$ ) and they were grown for an additional $\sim 7 \mathrm{~h}$. Cells were harvested on the third day at $11000 \times \mathrm{g}$ for $10 \mathrm{~min}$ in $500 \mathrm{~mL}$ centrifuge bottles, weighted and either frozen at $-80^{\circ} \mathrm{C}$ or lysed immediately for purification.

Cells were lysed in $50 \mathrm{mM}$ MOPS (pH 7.0) containing $1 \mathrm{mM}$ EDTA, $1 \mathrm{mg} / \mathrm{ml}$ lysozyme, 1 $\mathrm{mM}$ PMSF and $0.5 \mathrm{mM}$ DTT, filtered using $0.22 \mu \mathrm{m}$ SteriTop vacuum filters (Millipore) and loaded unto an HPLC DEAE anion exchange column. The bound protein was then washed with $10 \mathrm{mM} \mathrm{NaCl}$ followed by $30-35 \mathrm{mM} \mathrm{NaCl}$ (in $50 \mathrm{mM}$ MOPS), each time washing until absorbance intensities at 215 and $280 \mathrm{~nm}$ decreased back to baseline. The protein was then eluted with a gradient to $115 \mathrm{mM} \mathrm{NaCl}$ in approximately one column volume, monitored via absorbance at $415 \mathrm{~nm}$. Fractions were pulled together and concentrated using $30 \mathrm{KDa}$ Centricon centrifugal filter units (Millipore) to $3 \mathrm{~mL}$ or less. The concentrated protein was passed through a $0.22 \mu \mathrm{m}$ filter, loaded onto an HPLC gel filtration column and eluted (Absorbance of protein monitored at $415 \mathrm{~nm}$ ). The eluted fractions were again pulled together and endotoxins were removed with Pierce High Capacity Endotoxin Columns. To further decrease the endotoxin levels, an extra step of hydrophobic capture using a Butyl-HP sepharose column (GE Healthcare) was eventually included. Protein samples were loaded in $50 \mathrm{mM}$ sodium phosphate buffer ( $\mathrm{pH}$ 7.2) with $2 \mathrm{M} \mathrm{NaCl}$. The protein was washed with the same buffer and then eluted with a gradient from $50 \mathrm{mM}$ sodium phosphate buffer ( $\mathrm{pH} 7.2)$ with $2 \mathrm{M} \mathrm{NaCl}$ to $10 \mathrm{mM}$ sodium phosphate buffer (pH 7.2) without $\mathrm{NaCl}$.

After endotoxin removal, an excess amount of ferricyanide was added to oxidize the protein and removed by a gravity size-exclusion column (Econopac 10DG, BioRad). For in vitro experiments, the oxidized protein was concentrated and frozen at $-80^{\circ} \mathrm{C}$. SDS-PAGE was used as purity criteria. The protein yields were similar to wild type $\mathrm{Ngb}$ and we do not observe significant stability changes (i.e. protein aggregation) in the $4-37^{\circ} \mathrm{C}$ temperature range. For in vivo experiments, the protein was further reduced by an excess amount of sodium dithionite. For infusions of deoxy-Ngb-H64Q-CCC, the sodium dithionite was removed by a gravity size-exclusion column (Econopac 10DG, BioRad) inside an anaerobic globe box. The protein was then concentrated inside the glove box, sealed inside anaerobic glass vials and frozen at $-80^{\circ} \mathrm{C}$. For infusing oxy- $\mathrm{Ngb}$, the sodium dithionite was removed 
from the protein at $4{ }^{\circ} \mathrm{C}$ in atmospheric conditions. The $\mathrm{Ngb}$ was then concentrated, in atmospheric conditions, at $4{ }^{\circ} \mathrm{C}$ to slow down autoxidation and frozen at $-80{ }^{\circ} \mathrm{C}$. Then, the protein, was exposed to cycles of vacuum and nitrogen gas to remove dissolved oxygen, sealed in glass vials, and replaced at $-80{ }^{\circ} \mathrm{C}$.

\section{Preparation of reduced, oxidized and ligand bound neuroglobin and hemoglobin}

Thawed Ngb-H64Q-CCC was mixed with an excess of potassium ferricyanide and passed through a desalting column to obtain the oxidized (met) form. Ferrous deoxy-Ngb was obtained by adding an excess of sodium dithionite to the oxidized form. For aerobic experiments, the oxygen-bound form was obtained by passing the ferrous deoxy form through a desalting column (PD spin trap G-25, GE Healthcare) under aerobic conditions immediately before mixing with $\mathrm{CO}-\mathrm{Hb}$. $\mathrm{CO}-\mathrm{Hb}$ was obtained by adding an excess of sodium dithionite to degassed, oxygen-bound $\mathrm{Hb}$ and diluting with $\mathrm{PBS}$ containing an excess of dissolved $\mathrm{CO}$. To remove remaining dissolved $\mathrm{CO}$ the $\mathrm{CO}-\mathrm{Hb}$ solution was passed through a desalting column inside an anaerobic glove box and sodium dithionite was added back to $\mathrm{CO}-\mathrm{Hb}$ in case of anaerobic experiments.

\section{Preparation of apo-neuroglobin}

Heme-free $\mathrm{Ngb}$ was prepared by the acid-acetone method as previously described (58). A solution of acetone $(100 \mathrm{ml})$ was acidified with $1 \mathrm{ml}$ of $2 \mathrm{M} \mathrm{HCl}$ and pre cooled to $-20{ }^{\circ} \mathrm{C} .50$ $\mu \mathrm{l}$ of Ngb-H64Q-CCC $10 \mathrm{mM}$ were added to the acetone solution under stirring. The solution was centrifuged at $10000 \times \mathrm{g}$ for $5 \mathrm{~min}$ and the precipitate was resuspended again in acidified acetone until clear. The white precipitate was finally resuspended in cold water and buffer exchanged using $10 \mathrm{KDa}$ Centricon centrifugal filter units (Millipore) first to $0.1 \%$ sodium bicarbonate in water and then to PBS. The final concentrated protein was centrifuged at $16000 \times \mathrm{g}$ for $5 \mathrm{~min}$ to remove any insoluble protein. The concentration of the protein was assessed in $6 \mathrm{M}$ guanidine hydrochloride using an extinction coefficient of $22190 \mathrm{M}^{-1} \mathrm{~cm}^{-1}$ at $280 \mathrm{~nm}$ according to Edelhoch (59).

\section{Determination of neuroglobin $\mathrm{CO}$ and Oxygen binding affinities}

Flash photolysis was used to determine the on-rate of $\mathrm{CO}$ on $\mathrm{Hb}$ and both $\mathrm{Ngb}$ mutants. Standard spectra determined as described in the "Least squares deconvolution" section were used to monitor the species formed during the reaction. For these experiments, the samples of wild type and recombinant $\mathrm{Ngbs}$ (described below) and $\mathrm{Hb}$ are saturated with $\mathrm{CO}$ gas and then were photolysed with a $20 \mathrm{~mJ} 6 \mathrm{~ns}$ Nd-YAG laser pulse at $532 \mathrm{~nm}$ and the CO recombination kinetics were recorded using an extremely fast streak camera which collects spectral data with submicrosecond time resolution, with fits to first order kinetics using global analysis employing SpecFit software $(27,28,30)$. Each protein was diluted into a phosphate buffer containing $10 \mathrm{mM}$ sodium dithionite that had been de-gassed with $\mathrm{CO}$. The samples remained under $\mathrm{CO}$ pressure for an additional 15 minutes and then were photolysed. The recombination kinetics was recorded for $1200 \mu$ s and $100 \mu$ s for $\mathrm{Hb}$ and $\mathrm{Ngb}$, respectively. The resultant absorption difference spectra (transient minus ground state) was fit to first order kinetics using global analysis employing SpecFit software (60). To further investigate the binding kinetics, the Ngb-H64Q-CCC was incubated under $0.1 \mathrm{~atm} \mathrm{CO}$ and the above assay was repeated with the same laser parameters. The time scale was changed to 
0-3 ms and 0-6 $\mathrm{ms}$ for $\mathrm{Ngb}$ and $\mathrm{Hb}$, respectively. The bimolecular rate constant for oxygen binding was determined similarly as that for $\mathrm{CO}$ binding and as described previously (61). $\mathrm{Ngb}-\mathrm{H} 64 \mathrm{Q}-\mathrm{CCC}$ was equilibrated with one atmosphere of CO $(200 \mu \mathrm{M} \mathrm{Ngb}$ and $1 \mathrm{mM}$ $\mathrm{CO}$ ). This sample was diluted 1:10 in air-equilibrated phosphate buffered saline so the final concentration of Ngb-H64Q-CCC was $20 \mu \mathrm{M}$ and the final oxygen concentration was 225 $\mu \mathrm{M}$. The laser was used to photolyse $\mathrm{CO}$ and oxygen recombination kinetics were observed for $30 \mu$ s following photolysis.

Absorption spectroscopy kinetics was used to determine the off-rate of $\mathrm{CO}$ on both $\mathrm{Ngb}$ mutants, as well as $\mathrm{Hb}$. Samples of $10 \mu \mathrm{M}$ protein and $100 \mu \mathrm{M}$ sodium dithionite were saturated with $\mathrm{CO}$. Then $1 \mathrm{mM}$ NO solution was prepared using ProliNONOate (Cayman Chemical \# 82145) and was injected into each sample and immediately scanned on a Cary50 spectrophotometer. Absorption spectra were recorded for 45 minutes and 270 minutes for $\mathrm{Hb}$ and $\mathrm{Ngb}$, respectively. The data was once again fit to first order using SpecFit software.

\section{Determination of oxygen dissociation kinetics}

The rate of oxygen dissociation from Ngb-H64Q-CCC was determined by ligand replacement. The experiments were carried out at $25^{\circ} \mathrm{C}$ in an Applied Photophysics SX-20 stopped-flow spectrophotometer with a diode array detector (Applied Photophysics Ltd.) contained in an anaerobic glove box (Coy Laboratory Products). $100 \mathrm{mM}$ sodium phosphate buffer, $\mathrm{pH} 7.4$ was used for all the solutions. The Ngb samples were reduced by excess sodium dithionite in the glove box and the deoxy-Ngb was run through a gravity sizeexclusion column (Econopac 10DG, BioRad) to remove the excess of reductant. The protein was mixed with air-saturated buffer $\left(\left[\mathrm{O}_{2}\right] \approx 260 \mu \mathrm{M}\right)$ in $1: 4(\mathrm{v} / \mathrm{v})$ or $1.5: 1(\mathrm{v} / \mathrm{v})$ ratios to form quantitatively the Ngb-oxy complex and achieve final oxygen concentrations of $\approx 208 \mu \mathrm{M}$ $(1: 4)$ or $\approx 104 \mu \mathrm{M}(1.5 / 1)$. This sample was then mixed different concentrations of $\mathrm{CO}$ buffer made by mixing CO-saturated buffer $([\mathrm{CO}] \approx 1 \mathrm{mM})$ and anaerobic buffer in the stopped-flow instrument. The spectrum in the visible range $(350-730 \mathrm{~nm})$ was sampled every $1.24 \mathrm{~ms}$ for a reaction time of $1 \mathrm{~s}$. Spectral changes were consistent with a decay of the Ngb-oxy complex to form the Ngb-CO species. Traces over the whole spectral range (300-730nm) where fitted simultaneously for each experiment using the Pro-K software (Applied Photophysics Ltd.) to calculate the observed oxygen dissociation rate.

\section{Hemoglobin-to-neuroglobin $\mathrm{CO}$ transfer kinetics}

Free $\mathrm{Hb}$ kinetics- $\mathrm{CO}-\mathrm{Hb}$ was prepared by adding an excess of sodium dithionite to thawed $\mathrm{Hb}$ and mixing with $\mathrm{CO}$-saturated buffer in a ratio of at least 1:4 (1 volume of $\mathrm{Hb}$ to 4 volumes of $\mathrm{CO}$ saturated buffer). Excess $\mathrm{CO}$ was removed by passing through a desalting column inside an anaerobic glove box. For anaerobic experiments an excess of sodium dithionite was then added to the $\mathrm{CO}-\mathrm{Hb}$. To measure $\mathrm{CO}$ transfer kinetics, $\mathrm{CO}-\mathrm{Hb}$ inside a cuvette of $1 \mathrm{~cm}$ path length was placed in the cell holder of a Cary 50 spectrophotometer at $37^{\circ} \mathrm{C}$. The reaction was initiated by injecting $\mathrm{Ngb}$ into the $\mathrm{CO}-\mathrm{Hb}$ solution for a final concentration of $30-40 \mu \mathrm{M}$ of both proteins.

Red Blood Cell kinetics-RBCs were obtained by washing $50-100 \mu \mathrm{L}$ of packed RBCs with PBS 3 to 5 times by centrifugation at $2000 \times \mathrm{g}$ for $<1 \mathrm{~min}$. The washed RBCs were 
diluted in 1 to $2 \mathrm{ml}$ of PBS and deoxygenated while on ice and slowly stirring by a passing flow of argon gas for up to $60 \mathrm{~min}$. Sodium dithionite was then added to the RBCs such that the concentration after dilution in CO-buffer would not exceed $7 \mathrm{mM}$. RBC-encapsulated $\mathrm{CO}-\mathrm{Hb}$ was obtained by diluting the deoxygenated $\mathrm{RBC}$ solution with a ratio of at least 4:1 (v/v) of CO buffer to RBCs. Excess $\mathrm{CO}$ was removed by diluting the RBCs 5-fold with degassed PBS (containing 5-10 mM sodium dithionite for anaerobic experiments), followed by centrifugation and removal of the supernatant. Afterwards, the RBCs were resuspended to a final concentration of $100-300 \mu \mathrm{M}$ in heme, with an excess of sodium dithionite for anaerobic experiments. RBCs with $100 \% \mathrm{CO}-\mathrm{Hb}$ were equilibrated to $37{ }^{\circ} \mathrm{C}$ in a $1 \mathrm{~cm}$ septum-capped cuvette inside the cell holder of a Cary 50 spectrophotometer and the reaction was initiated by injecting Ngb-H64Q-CCC into the RBC solution. Sets of experiments with ratios of $\mathrm{Ngb}$ to $\mathrm{Hb}$ of $0.5,1,1.5$ and 5.6:1 (in heme) were performed. The reaction mixture contained $2-10 \mathrm{mM}$ sodium dithionite under anaerobic conditions, while under aerobic conditions the cap was removed from the cuvette before injecting Ngb-H64QCCC. All reaction mixtures were stirred continuously. $0.3 \mathrm{~mL}$ samples were removed from the reaction mixture in immediate succession and, after centrifugation, supernatants were removed and saved in pre-labeled microcentrifuge tubes, while $0.3 \mathrm{~mL}$ of $10 \mathrm{mM}$ sodium dithionite with $0.5 \%$ NP40 in PBS was added to the RBC pellets for cell lysis and absorbance measurement. Absorbance measurement of the saved supernatants and lysed RBC pellets was initiated immediately after centrifugation of the last time point. Control experiments were performed similarly, but without addition of Ngb mutants.

\section{Mouse hemoglobin preparation}

Mouse $\mathrm{Hb}$ were prepared as reported for human $\mathrm{Hb}$ (26). In short, mouse RBCs were washed with PBS, and lysed hypotonically by dilution with excess $\mathrm{H}_{2} \mathrm{O}$. The lysed RBCs were centrifuged at $7000 \times g$ to remove cell debris. The resulting solution, consistent of mostly $\mathrm{Hb}$, was concentrated and buffer exchanged using Amicon Ultra centrifugal filters (Millipore) with a cutoff of $50 \mathrm{kDa}$ in order to remove low molecular weight contaminants. Samples were aliquoted and frozen in liquid $\mathrm{N}_{2}$ and stored at $-80^{\circ} \mathrm{C}$.

\section{Least squares deconvolution}

Standard reference spectra of the oxidized (met), ferrous (deoxy), oxygenated $\left(\mathrm{O}_{2}\right.$-bound), carboxy (CO-bound), and nitrosylated (NO-bound) forms of human $\mathrm{Hb}$, mouse $\mathrm{Hb}$ and $\mathrm{Ngb}$ were obtained. The reference species for each species were obtained as follows: after thawing protein on ice, spectra of the oxidized species were obtained by mixing with an excess of potassium ferricyanide and passing through a gravity size-exclusion column (Econopac 10DG, BioRad). Spectra of deoxy species were recorded after adding an excess of sodium dithionite to the oxidized form $(2-5 \mathrm{mM})$. Spectra of the oxygenated form were recorded immediately after passing a sample of the deoxy species through the size-exclusion column under aerobic conditions at $4{ }^{\circ} \mathrm{C}$.

Spectra of the CO-bound species were measured after mixing the deoxy proteins with COsaturated buffer in a ratio of 1:4. Spectra of the nitrosylated (NO-bound) species were obtained as for the CO-species adding NO-saturated buffer instead of CO-saturated buffer. All standard spectra were collected on a Cary 50 spectrophotometer. Spectral deconvolution 
of time-resolved absorption data collected at 22,25 or $37^{\circ} \mathrm{C}$ was performed by a least squares fit using basis spectra as described previously $(12,27-30)$. We used two methods to evaluate the accuracy of the deconvolution. First, we kept the total concentration of $\mathrm{Hb} / \mathrm{Ngb}$ constant through the reaction based on the initial concentration. Secondly, the results were double checked by fitting the spectra in two different wavelength ranges, typically 490 to 650 and 450 to 700 . For both $\mathrm{Hb}$ and Ngb-H64Q-CCC the oxidized and diatomic ligandbound forms were also converted to denatured forms, which have the same absorbance spectra of an oxidized heme, with the QuantiChrom Heme Assay Kit (BioAssay Systems). All of the basis spectra were standardized to an absorbance of $\mathrm{mM}^{-1} \mathrm{~cm}^{-1}$ using an extinction coefficient of $68.1 \mathrm{mM}^{-1} \mathrm{~cm}^{-1}$ of the oxidized heme. This extinction coefficient was calculated by converting the same solution of met-globin to the denatured, oxidized heme, form and to cyanomet heme. The extinction coefficient used for cyanomet heme was $11 \mathrm{mM}^{-1} \mathrm{~cm}^{-1}$ at $540 \mathrm{~nm}$ (62) Deconvolution of experimental spectra was performed with a least-squares fitting routine in Microsoft Excel. Because the change in absorbance of some kinetic experiments is small, all spectra composed of both $\mathrm{Hb}$ and Ngb-H64Q-CCC were always fit between 450 and $700 \mathrm{~nm}, 490$ and $650 \mathrm{~nm}$, and 510 and $600 \mathrm{~nm}$; with and without constraining the $\mathrm{Hb}$ and Ngb-H64Q-CCC concentrations to be equal to each other (for equimolar experiments) and to their pre-calculated concentrations, in order to confirm the accuracy of the deconvolution. For the same purpose, sometimes, a parameter that could shift the spectra horizontally, along the wavelength axis, was also included in the fit (not used in any of the data shown). Absorbance spectra from anaerobic experiments were deconvoluted using CO- and deoxy- standards of $\mathrm{Hb}$ and Ngb-H64Q-CCC.

Absorbance spectra from aerobic experiments were deconvoluted using the standards of the oxidized, CO-bound and oxygenated forms of $\mathrm{Hb}$ and Ngb-H64Q-CCC. For the RBC experiments where $\mathrm{Hb}$ was separated from $\mathrm{Ngb}$ and sodium dithionite was afterwards added to either RBCs in aerobic experiments or to the supernatant in anaerobic experiments, deoxy standards were used in deconvolution instead of the oxy- and met- forms.

\section{Modeling of neuroglobin structures}

The structure of wild type human Ngb was modeled using the Swiss model server (63) with the reported structure for the $\mathrm{C} 46 \mathrm{G} / \mathrm{C} 55 \mathrm{~S} / \mathrm{C} 120 \mathrm{~S}$ mutant (PDB:1OJ6) (64) as template. The unliganded Ngb-H64Q structure was modeled using the PyMOL mutagenesis tool (65) on the previous model for the Ngb wild type structure. The Ngb-H64Q model with bound CO was built from the CO-bound wild type Ngb structure (PDB: 1W92) (66) using the PyMOL mutagenesis tool (65) to introduce the H64Q mutation.

\section{Non-lethal CO poisoning mouse model}

Male C57BL/6 wild-type mice (10-12 week) were obtained from The Jackson Laboratory (Bar Harbor, ME). All studies were performed using protocols approved by the Institutional Animal Care and Use Committee at the University of Pittsburgh and in accordance with National Institutes of Health guidelines. Mice were anesthetized with inhaled 2\% isoflurane, and micro-renathane catheters (MRE-025; Braintree Scientific) were inserted into the left femoral artery and vein, sutured in place, stabilized with superglue, tunneled subcutaneously to exit the skin at the upper back, taped to a wire attached to posterior cervical muscles for 
stiffness (792500; A-M Systems), and connected to a 360 degree dual channel swivel designed for mice (375/D/22QM; Instech).

Catheter patency was maintained by continuous sterile infusion of $7 \mathrm{ul} / \mathrm{h}$ saline containing 20 units/ml heparin (APP Pharmaceuticals) using a syringe pump with multisyringe adaptor (R99-EM; Razel Scientific Instruments). CO exposure was performed in conscious mice after three days recovery from catheter implantation. Mice were randomly allocated to PBS or $\mathrm{Ngb}$ treatment with similar body weight without blinding. Mice were exposed to 1500 ppm of CO equilibrated in $21 \%$ oxygen and $79 \%$ nitrogen (Matheson Inc.) in an individual customized chamber in which gas entered through inlet ports in the base and exhausted through an open hole at the apex (67). Blood samples for $\mathrm{CO}-\mathrm{Hb}$ measures were collected by first drawing a $70 \mu \mathrm{L}$ volume from the arterial catheter to clear the dead space, followed by $20 \mu \mathrm{L}$ of blood (by a different $25 \mu \mathrm{L}$ syringe) at various time points. $5 \mu \mathrm{L}$ of the drawn blood were washed and the absorbance spectrum was immediately measured at 200-fold dilution and deconvoluted to calculate the percentage of $\mathrm{CO}-\mathrm{Hb}$ out of the total amount of $\mathrm{Hb}(\mathrm{CO}-\mathrm{Hb} \%)$. After an average 50 minutes of $\mathrm{CO}$ exposure, the animals were returned to normal atmospheric conditions and a $275 \mu \mathrm{L}$ infusion (delivering $250 \mu \mathrm{L}$ to the animals) of either PBS or Ngb-H64Q-CCC was started for 4 minutes through venous catheter. Blood samples were collected every 10 minutes during $\mathrm{CO}$ exposure, every 5 minutes for $30 \mathrm{~min}$ after exposure and again every 10 minutes until the $\mathrm{CO}-\mathrm{Hb}$ levels decreased below $10 \%$. At this point the animals were sacrificed and urine (if present) was immediately drawn from the bladder for analysis. Blood sample supernatants were stored on dry ice until after the end of an experiment, when measured via absorption (to check for cell lysis via presence of $\mathrm{Hb}$ and for $\mathrm{CO}-\mathrm{Ngb})$.

In the toxicological study, male C57BL/6 wild-type mice were exposed to $4000 \mathrm{ppm}$ for 15 minutes. Ngb-H64Q-CCC was administrated at $9-10 \mathrm{mM}$ in $250 \mathrm{ul}$ by retro-orbital injection after $\mathrm{CO}$ exposure and mice were sacrificed at $48 \mathrm{~h}$ for blood and tissue collection (kidney, liver, heart, brain and lung). Fresh blood samples were sent for tests of complete blood counts (CBC, Hemavet 950FS) and plasma samples were sent for blood chemistry panel test (including creatinine, AST/ALT, urea and phosphorus).

\section{Lethal CO poisoning mouse model}

Male C57BL/6 wild-type mice were used at a mean age of 10-13 weeks and, mean weight of 23.4-27.4 g. The experimental protocol was approved by the Institutional Animal Care and Use Committee at the University of Pittsburgh and in accordance with National Institutes of Health guidelines. Ngb-H64Q-CCC was reduced anaerobically by excess sodium dithionite, removed by a gravity size-exclusion column (Econopac 10DG, BioRad) and concentrated with Amicon Ultra centrifugal filters ( $0.5 \mathrm{ml}, 10 \mathrm{KDa}$ cutoff, Millipore). Sodium dithionite was added at substoichiometric concentrations to the Ngb-H64Q-CCC after desalting so that its concentration was between 1.25 to $2.5 \mathrm{mM}$. Ngb-H64Q-CCC concentration and the percentage of met-Ngb was confirmed spectrophotometrically, with least-squares deconvolution using component reference spectra. The Ngb-H64Q-CCC solutions of $11.6 \pm 0.6 \mathrm{mM}$ with the met-Ngb-H64Q-CCC form maintained at only 4.09 $\pm 1.55 \%$ in an infusion volume of $10 \mu \mathrm{l} / \mathrm{g}$ mouse weight were loaded into a $1 \mathrm{ml}$ insulin 
syringe (U-100, BD) anaerobically, the needle sealed with rubber, and frozen at $-80^{\circ} \mathrm{C}$ until ready for infusion. Albumin $(5 \mathrm{mM})$ and PBS were used as controls with sodium dithionite concentration of $2.5 \mathrm{mM}$. The mice were anesthetized by isoflurane, a tracheal tube placed followed by cannulation of right jugular vein and left carotid artery. Arterial blood pressure was monitored and recorded (DATAQ instruments) through a catheter in the carotid artery.

An intravenous catheter was placed and used for Ngb-H64Q-CCC or control PBS infusions using a syringe pump. Infusion volume was calculated according to the mouse weight (10 $\mu \mathrm{l} / \mathrm{g}$ ) and dead volume of the catheter.

Ventilation was initiated after the surgery with a volume controlled ventilator (MiniVent, Type 845; Hugo Sachs). Air was administrated (21\% oxygen) with $1.5 \%$ isoflurane at tidal volumes of $228 \sim 270 \mu \mathrm{l}(8.8 \mu \mathrm{l} / \mathrm{g}$ weight $)$ and respiratory frequencies of $175 \mathrm{BPM}$. Three percent (3\%) $\mathrm{CO}$ was delivered in air for 4.5-minutes via the ventilator. After $\mathrm{CO}$ delivery the ventilator delivered air without $\mathrm{CO}$ and the Ngb-H64Q-CCC or PBS control was infused for 2-minutes. Arterial blood pressure and heart rate signals were processed using Labchart software (ADInstruments Ltd.). Mortality was established based on an unmeasurable heart rate and blood pressure for 5 minutes and all mice were followed for a pre-defined experimental observation period of 40-minutes from $\mathrm{CO}$ exposure, followed by sacrifice.

\section{Blood lactate analysis in the lethal $\mathrm{CO}$ poisoning model}

Using the lethal $\mathrm{CO}$ poisoning mouse model, we measured the lactate levels as a marker of tissue perfusion and oxygen delivery. Blood was withdrawn from the arterial catheter in the carotid artery at the following time points: prior to the commencement of the infusion of treatment with PBS, albumin or Ngb-H64Q-CCC (level drawn between 4.5 and 6.5 minutes). 9.5, 14.5, 19.5, 24.5 and 40.0 minutes from the commencement of $\mathrm{CO}$ exposure. Lactate was measured using the Lactate Plus Professional Lactate Reader (Lactate.com), results are reported in millimoles per liter $(\mathrm{mM})$.

\section{Western blotting}

Mice tissue samples (kidney, liver, brain, heart and lung) were lysed in ice-cold lysis buffer [20 mmol/L Tris pH 7.5, $150 \mathrm{mmol} / \mathrm{L} \mathrm{NaCl}, 1 \mathrm{mmol} / \mathrm{L}$ EDTA, $1 \mathrm{mmol} / \mathrm{L}$ EGTA, $1 \%$ Triton $\mathrm{X}-100,2.5 \mu \mathrm{mol} / \mathrm{L}$ Na-pyrophosphate, $1 \mathrm{mmol} / \mathrm{L} \beta$-glycerophosphate, $1 \mathrm{mmol} / \mathrm{L} \mathrm{Na3VO} 4,1$ $\mathrm{mmol} / \mathrm{L}$ phenylmethylsulfonyl fluoride, $1 \mu \mathrm{g} / \mathrm{mL}$ Complete Protease Inhibitor Cocktail (Roche Applied Science). Protein lysates (100 $\mu$ g total protein) were separated on a 4-12\% SDS Bis-Tris protein gel under reducing conditions, followed by electrotransfer to a nitrocellulose membrane. After blocking, the membranes were probed with rabbit anti-Ngb polyclonal antibody (sc-30144, Santa Cruz Biotechnology, Inc.). Purified Ngb-H64Q-CCC was used as a positive control.

\section{Histology}

Mouse kidney tissues were fixed in formalin for $24 \mathrm{~h}$, embedded in paraffin and cut into 4 $\mu \mathrm{m}$ sections. The slides were stained with hematoxylin and eosin (H\&E) and examined under light microscope. 


\section{Statistical analysis}

Data are presented as means \pm SEM and were analyzed by unpaired Student's $t$-test or oneway ANOVA unless indicated otherwise. Statistical analyses were performed using GraphPad Prism software version 6.0. A mixed effect model with unstructured covariance was applied to determine time treatment (Ngb vs. PBS) interaction and the effect of treatment after drug infusion (time $>0$ ) for blood pressure data. Two-way ANOVA with repeated measures was performed to determine the effects of treatment (Ngb, PBS, and albumin), time and interaction of these values on lactate levels. $P$ values $<0.05$ were considered significant.

\section{Supplementary Material}

Refer to Web version on PubMed Central for supplementary material.

\section{Acknowledgments}

We thank Venkata Ragireddy and Bonnie Lemster for help with the protein expression and purification. We thank for David Osei-Hwedieh for assistance with mice injection. We also thank Catherine Corey and Erin Schwoegl (University of Pittsburgh) for help with some experiments and Dr. Richard Williams, Crystal Bolden and Lauren Nelson (Wake Forest University Department of Physics) for help with laser flash photolysis experiments. We also acknowledge an anonymous reviewer for the mathematical description of the $\mathrm{CO}$ binding process included in Methods section of the Supplementary Materials.

Funding: This work is supported in part by resources provided by the NHLBI SMARTT (Science Moving TowArd Research Translation and Therapy) Program; the Institute for Transfusion Medicine, and the Hemophilia Center of Western Pennsylvania to M.T.G. Additional support was provided by NIH grants F32 HL132418 to J.J.R., R01 HL111706 to C.P.O'D., R01 GM113816 to S.S., R21 ES027390 to J.T., R01 HL058091 to D.B.K.-S., and R01 HL098032, R01 HL125886, P01 HL103455, T32 HL110849, and T32 HL007563 to M.T.G.

\section{REFERENCES AND NOTES}

1. Hampson NB, Piantadosi CA, Thom SR, Weaver LK. Practice recommendations in the diagnosis, management, and prevention of carbon monoxide poisoning. Am J Respir Crit Care Med. 2012; 186:1095-1101. [PubMed: 23087025]

2. Bernard, C. Leçons Sur les Effets des Substances Toxiques et Médicamenteuses. Paris: Bailliere; 1857.

3. Haldane J. The relation of the action of carbon monoxide to oxygen tension. J Physiol (London). 1895:201-217.

4. Blumenthal I. Carbon monoxide poisoning. J R Soc Med. 2001; 94:270-272. [PubMed: 11387414]

5. Weaver LK, Valentine KJ, Hopkins RO. Carbon monoxide poisoning: risk factors for cognitive sequelae and the role of hyperbaric oxygen. Am J Respir Crit Care Med. 2007; 176:491-497. [PubMed: 17496229]

6. Weaver LK, Hopkins RO, Chan KJ, Churchill S, Elliott CG, Clemmer TP, Orme JF Jr, Thomas FO, Morris AH. Hyperbaric oxygen for acute carbon monoxide poisoning. N Engl J Med. 2002; 347:1057-1067. [PubMed: 12362006]

7. Rose JJ, Wang L, Xu Q, McTiernan CF, Shiva S, Tejero J, Gladwin MT. Carbon Monoxide Poisoning: Pathogenesis, Management and Future Directions of Therapy. Am J Respir Crit Care Med. in press.

8. Burmester T, Weich B, Reinhardt S, Hankeln T. A vertebrate globin expressed in the brain. Nature. 2000; 407:520-523. [PubMed: 11029004]

9. Bentmann A, Schmidt M, Reuss S, Wolfrum U, Hankeln T, Burmester T. Divergent distribution in vascular and avascular mammalian retinae links neuroglobin to cellular respiration. J Biol Chem. 2005; 280:20660-20665. [PubMed: 15793311] 
10. Nienhaus K, Nienhaus GU. Searching for neuroglobin's role in the brain. IUBMB Life. 2007; 59:490-497. [PubMed: 17701543]

11. Raychaudhuri S, Skommer J, Henty K, Birch N, Brittain T. Neuroglobin protects nerve cells from apoptosis by inhibiting the intrinsic pathway of cell death. Apoptosis. 2010; 15:401-411. [PubMed: 20091232]

12. Tiso M, Tejero J, Basu S, Azarov I, Wang X, Simplaceanu V, Frizzell S, Jayaraman T, Geary L, Shapiro C, Ho C, Shiva S, Kim-Shapiro DB, Gladwin MT. Human neuroglobin functions as redoxregulated nitrite reductase. J Biol Chem. 2011; 286:18277-18289. [PubMed: 21296891]

13. Burmester T, Hankeln T. What is the function of neuroglobin? J Exp Biol. 2009; 212:1423-1428. [PubMed: 19411534]

14. Dewilde S, Kiger L, Burmester T, Hankeln T, Baudin-Creuza V, Aerts T, Marden MC, Caubergs R, Moens L. Biochemical characterization and ligand binding properties of neuroglobin, a novel member of the globin family. J Biol Chem. 2001; 276:38949-38955. [PubMed: 11473128]

15. Trent JT 3rd, Hargrove MS. A ubiquitously expressed human hexacoordinate hemoglobin. J Biol Chem. 2002; 277:19538-19545. [PubMed: 11893755]

16. Trevaskis B, Watts RA, Andersson CR, Llewellyn DJ, Hargrove MS, Olson JS, Dennis ES, Peacock WJ. Two hemoglobin genes in Arabidopsis thaliana: the evolutionary origins of leghemoglobins. Proc Natl Acad Sci U S A. 1997; 94:12230-12234. [PubMed: 9342391]

17. de Sanctis D, Dewilde S, Vonrhein C, Pesce A, Moens L, Ascenzi P, Hankeln T, Burmester T, Ponassi M, Nardini M, Bolognesi M. Bishistidyl heme hexacoordination, a key structural property in Drosophila melanogaster hemoglobin. J Biol Chem. 2005; 280:27222-27229. [PubMed: 15917230]

18. Tejero J, Sparacino-Watkins CE, Ragireddy V, Frizzell S, Gladwin MT. Exploring the mechanisms of the reductase activity of neuroglobin by site-directed mutagenesis of the heme distal pocket. Biochemistry. 2015; 54:722-733. [PubMed: 25554946]

19. Nienhaus K, Kriegl JM, Nienhaus GU. Structural dynamics in the active site of murine neuroglobin and its effects on ligand binding. J Biol Chem. 2004; 279:22944-22952. [PubMed: 15016813]

20. Rohlfs RJ, Olson JS, Gibson QH. A comparison of the geminate recombination kinetics of several monomeric heme proteins. J Biol Chem. 1988; 263:1803-1813. [PubMed: 3338995]

21. Rohlfs RJ, Mathews AJ, Carver TE, Olson JS, Springer BA, Egeberg KD, Sligar SG. The effects of amino acid substitution at position E7 (residue 64) on the kinetics of ligand binding to sperm whale myoglobin. J Biol Chem. 1990; 265:3168-3176. [PubMed: 2303446]

22. Cooper CE. Nitric oxide and iron proteins. Biochim Biophys Acta. 1999; 1411:290-309. [PubMed: 10320664]

23. Van Doorslaer S, Dewilde S, Kiger L, Nistor SV, Goovaerts E, Marden MC, Moens L. Nitric oxide binding properties of neuroglobin. A characterization by EPR and flash photolysis. J Biol Chem. 2003; 278:4919-4925. [PubMed: 12480932]

24. Fago A, Mathews AJ, Dewilde S, Moens L, Brittain T. The reactions of neuroglobin with CO: evidence for two forms of the ferrous protein. J Inorg Biochem. 2006; 100:1339-1343. [PubMed: 16684569]

25. Cassoly R, Gibson Q. Conformation, co-operativity and ligand binding in human hemoglobin. J Mol Biol. 1975; 91:301-313. [PubMed: 171411]

26. Huang Z, Shiva S, Kim-Shapiro DB, Patel RP, Ringwood LA, Irby CE, Huang KT, Ho C, Hogg N, Schechter AN, Gladwin MT. Enzymatic function of hemoglobin as a nitrite reductase that produces NO under allosteric control. J Clin Invest. 2005; 115:2099-2107. [PubMed: 16041407]

27. Azarov I, He X, Jeffers A, Basu S, Ucer B, Hantgan RR, Levy A, Kim-Shapiro DB. Rate of nitric oxide scavenging by hemoglobin bound to haptoglobin. Nitric oxide. 2008; 18:296-302. [PubMed: 18364244]

28. Azarov I, Huang KT, Basu S, Gladwin MT, Hogg N, Kim-Shapiro DB. Nitric oxide scavenging by red blood cells as a function of hematocrit and oxygenation. J Biol Chem. 2005; 280:3902439032. [PubMed: 16186121]

29. Basu S, Azarova NA, Font MD, King SB, Hogg N, Gladwin MT, Shiva S, Kim-Shapiro DB. Nitrite reductase activity of cytochrome c. J Biol Chem. 2008; 283:32590-32597. [PubMed: 18820338] 
30. Kim-Shapiro DB, King SB, Huang Z, Louderback JG, Azizi F, Goyal M. Quantification of HbNO formation upon NO addition to oxyhemoglobin under physiological conditions. Blood. 2001; 98:16b-16b.

31. Kraut JA, Madias NE. Lactic acidosis. N Engl J Med. 2014; 371:2309-2319. [PubMed: 25494270]

32. Bosch X, Poch E, Grau JM. Rhabdomyolysis and acute kidney injury. N Engl J Med. 2009; 361:62-72. [PubMed: 19571284]

33. Zinkham WH, Houtchens RA, Caughey WS. Carboxyhemoglobin levels in an unstable hemoglobin disorder (Hb Zurich): effect on phenotypic expression. Science. 1980; 209:406-408. [PubMed: 7384813]

34. Winter PM, Miller JN. Carbon monoxide poisoning. JAMA-J Am Med Assoc. 1976; 236:15021504.

35. Ernst A, Zibrak JD. Current concepts - Carbon monoxide poisoning. N Engl J Med. 1998; 339:1603-1608. [PubMed: 9828249]

36. Weaver LK, Howe S, Hopkins R, Chan KJ. Carboxyhemoglobin half-life in carbon monoxidepoisoned patients treated with $100 \%$ oxygen at atmospheric pressure. Chest. $2000 ; 117: 801-808$. [PubMed: 10713010]

37. Hampson NB, Hauff NM. Risk factors for short-term mortality from carbon monoxide poisoning treated with hyperbaric oxygen. Crit care med. 2008; 36:2523-2527. [PubMed: 18679118]

38. Hopkins RO, Weaver LK. Cognitive outcomes 6 years after acute carbon monoxide poisoning [abstract]. Undersea Hyperb Med. 2008:258.

39. Mimura K, Harada M, Sumiyoshi S, Tohya G, Takagi M, Fujita E, Takata A, Tatetsu S. Long-term follow-up study on sequelae of carbon monoxide poisoning; serial investigation 33 years after poisoning. Seishin Shinkeigaku Zasshi. 1999; 101:592-618. [PubMed: 10502996]

40. Weaver LK. Clinical practice. Carbon monoxide poisoning. N Engl J Med. 2009; 360:1217-1225. [PubMed: 19297574]

41. Weaver HR, Churchill LK, Deru SKK. Neurological outcomes 6 years after acute carbon monoxide poisoning [abstract]. Undersea Hyperb Med. 2008:258-259.

42. Gould SA, Moore EE, Moore FA, Haenel JB, Burch JM, Sehgal H, Sehgal L, DeWoskin R, Moss GS. Clinical utility of human polymerized hemoglobin as a blood substitute after acute trauma and urgent surgery. J Trauma-Injury Infect Crit Care. 1997; 43:325-331.

43. Noveck RJ, Shannon EJ, Leese PT, Shorr JS, Flaim KE, Keipert PE, Woods CM. Randomized safety studies of intravenous perflubron emulsion. II. Effects on immune function in healthy volunteers. Anesth Analg. 2000; 91:812-822. [PubMed: 11004031]

44. Olofsson C, Nygards EB, Ponzer S, Fagrell B, Przybelski R, Keipert PE, Winslow N, Winslow RM. A randomized, single-blind, increasing dose safety trial of an oxygen-carrying plasma expander (Hemospan (R)) administered to orthopaedic surgery patients with spinal anaesthesia. Transfus Med. 2008; 18:28-39. [PubMed: 18279190]

45. Zazzeron L, Liu C, Franco W, Nakagawa A, Farinelli WA, Bloch DB, Anderson RR, Zapol WM. Pulmonary Phototherapy for Treating Carbon Monoxide Poisoning. Am J Respir Crit Care Med. 2015; 192:1191-1199. [PubMed: 26214119]

46. Roderique JD, Josef CS, Newcomb AH, Reynolds PS, Somera LG, Spiess BD. Preclinical evaluation of injectable reduced hydroxocobalamin as an antidote to acute carbon monoxide poisoning. J Trauma Acute Care Surg. 2015; 79:S116-120. [PubMed: 26406423]

47. Kitagishi H, Negi S, Kiriyama A, Honbo A, Sugiura Y, Kawaguchi AT, Kano K. A diatomic molecule receptor that removes CO in a living organism. Angew Chem Int Ed Engl. 2010; 49:1312-1315. [PubMed: 20069620]

48. Goldbaum LR, Orellano T, Dergal E. Mechanism of the toxic action of carbon monoxide. Ann Clin Lab Sci. 1976; 6:372-376. [PubMed: 962299]

49. Brown SD, Piantadosi CA. In vivo binding of carbon monoxide to cytochrome c oxidase in rat brain. J Appl Phys. 1990; 68:604-610.

50. Brown SD, Piantadosi CA. Recovery of energy metabolism in rat brain after carbon monoxide hypoxia. J Clin Invest. 1992; 89:666-672. [PubMed: 1737854] 
51. Doherty DH, Doyle MP, Curry SR, Vali RJ, Fattor TJ, Olson JS, Lemon DD. Rate of reaction with nitric oxide determines the hypertensive effect of cell-free hemoglobin. Nat Biotechnol. 1998; 16:672-676. [PubMed: 9661203]

52. Alayash AI. Blood substitutes: why haven't we been more successful? Trends Biotechnol. 2014; 32:177-185. [PubMed: 24630491]

53. Huang Z, Louderback JG, Goyal M, Azizi F, King SB, Kim-Shapiro DB. Nitric oxide binding to oxygenated hemoglobin under physiological conditions. Bba-Gen Subjects. 2001; 1568:252-260.

54. Alayash AI. Oxygen therapeutics: can we tame haemoglobin? Nat Rev Drug Discov. 2004; 3:152159. [PubMed: 15043006]

55. Wang X, Tanus-Santos JE, Reiter CD, Dejam A, Shiva S, Smith RD, Hogg N, Gladwin MT. Biological activity of nitric oxide in the plasmatic compartment. Proc Natl Acad Sci U S A. 2004; 101:11477-11482. [PubMed: 15258287]

56. Vajpayee, GS.; Bem, NS. Basic Examination of Blood and Bone Marrow. In: McPherson, PM.; RA, editors. Henry's Clinical Diagnosis and Management by Laboratory Methods. 22. Vol. Chap 30. Saunders, an imprint of Elsevier Inc; Philadelphia, PA: 2011. p. 509-535.

57. Studier FW. Protein production by auto-induction in high-density shaking cultures. Protein Expr Purif. 2005; 41:207-234. [PubMed: 15915565]

58. Mu J, Li L, Guo Y, Qiu Z, Tan X. Spectroscopic study on acid-induced unfolding and refolding of apo-neuroglobin. Spectrochim Acta A Mol Biomol Spectrosc. 2010; 75:1600-1604. [PubMed: 20227336]

59. Edelhoch H. Spectroscopic determination of tryptophan and tyrosine in proteins. Biochemistry. 1967; 6:1948-1954. [PubMed: 6049437]

60. Hofrichter SJ, Henry JER, Eaton WA. Nanosecond absorption spectroscopy of hemoglobin: elementary processes in kinetic cooperativity. Proc Natl Acad Sci USA. 1983; 80:2235-2239. [PubMed: 6572974]

61. Birukou I, Schweers RL, Olson JS. Distal histidine stabilizes bound O2 and acts as a gate for ligand entry in both subunits of adult human hemoglobin. J Biol Chem. 2010; 285:8840-8854. [PubMed: 20080971]

62. Zijlstra WG, Vankampen EJ. Standardization of Hemoglobinometry .1. The extinction coefficient of Hemiglobincyanide at $\lambda=540 \mathrm{~m} \mu \varepsilon^{540} \mathrm{HiCN}$. Clin Chim Acta. 1960; 5:719-726. [PubMed: 13788465]

63. Schwede T, Kopp J, Guex N, Peitsch MC. SWISS-MODEL: An automated protein homologymodeling server. Nucleic Acids Res. 2003; 31:3381-3385. [PubMed: 12824332]

64. Pesce A, Dewilde S, Nardini M, Moens L, Ascenzi P, Hankeln T, Burmester T, Bolognesi M. Human brain neuroglobin structure reveals a distinct mode of controlling oxygen affinity. Structure. 2003; 11:1087-1095. [PubMed: 12962627]

65. DeLano, WL. The PyMOL molecular graphics system. 2002.

66. Vallone B, Nienhaus K, Matthes A, Brunori M, Nienhaus GU. The structure of carbonmonoxy neuroglobin reveals a heme-sliding mechanism for control of ligand affinity. Proc Natl Acad Sci U S A. 2004; 101:17351-17356. [PubMed: 15548613]

67. Polotsky VY, Rubin AE, Balbir A, Dean T, Smith PL, Schwartz AR, O’Donnell CP. Intermittent hypoxia causes REM sleep deficits and decreases EEG delta power in NREM sleep in the C57BL/6J mouse. Sleep Med. 2006; 7:7-16. [PubMed: 16309961]

68. Brantley RE Jr, Smerdon SJ, Wilkinson AJ, Singleton EW, Olson JS. The mechanism of autooxidation of myoglobin. J Biol Chem. 1993; 268:6995-7010. [PubMed: 8463233]

69. Kano K, Kitagishi H. HemoCD as an artificial oxygen carrier: oxygen binding and autoxidation. Artif Organs. 2009; 33:177-182. [PubMed: 19178464]

70. Mendes P. GEPASI: a software package for modelling the dynamics, steady states and control of biochemical and other systems. Comput Appl Biosci. 1993; 9:563-571. [PubMed: 8293329]

71. Parkhurst L. Hemoglobin and myoglobin ligand kinetics. Annu Rev Phys Chem. 1979; 30:503546. 
A

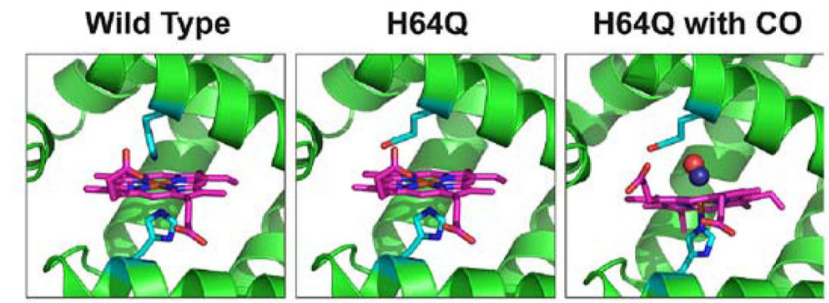

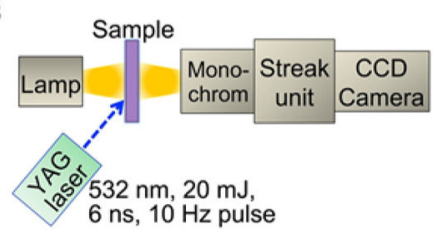

D

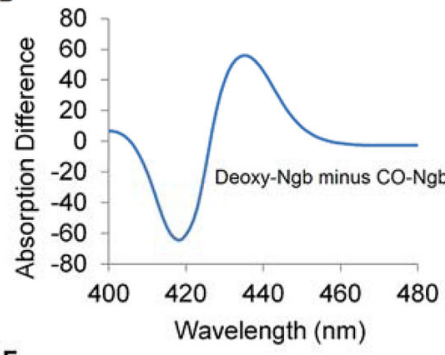

$\mathbf{F}$

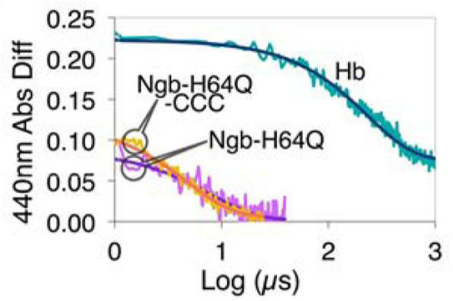

H

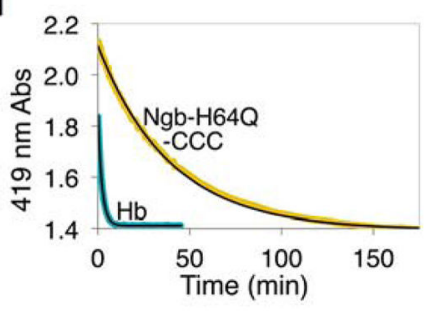

C

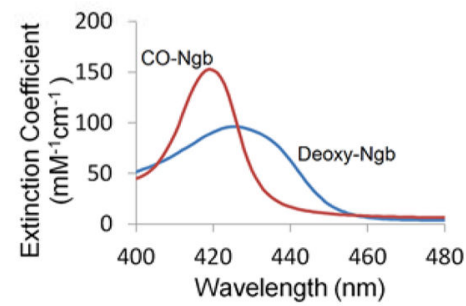

E

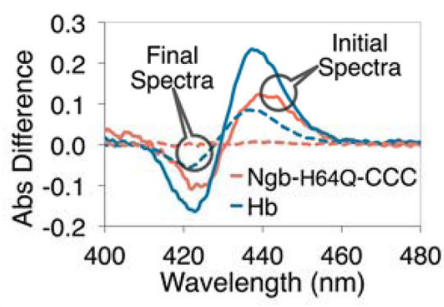

G
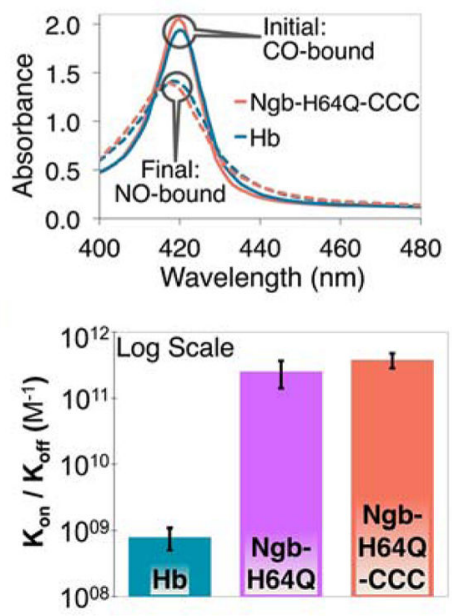

Fig. 1. Kinetics of association and dissociation of $\mathrm{CO}$ with hemoglobin and H64Q mutant neuroglobins

(A) Structure of wild-type Ngb and Ngb-H64Q mutant unliganded and with bound CO. Models for Ngb-H64Q and Ngb-H64Q-CO were built using available Ngb wild-type structures as described in Methods. (B) Flash Photolysis: A laser pulse dissociates CO from the heme. A mercury lamp is used to probe absorption. Light passes through the sample and then is diffracted onto a steak camera so that transmitted light is collected as a function of wavelength and time. For CO recombination kinetics were recorded for $1200 \mu \mathrm{s}, 100 \mu \mathrm{s}$, and $50 \mu$ s for hemoglobin, Ngb-H64Q, and Ngb-H64Q-CCC, respectively (C) Static absorption spectra of Ngb-H64Q-CCC. Spectra were normalized by concentrations to produce extinction coefficients. (D) Difference spectrum of deoxy-Ngb-H64Q-CCC minus CO-Ngb- 
H64Q-CCC. (E) Flash Photolysis: Difference between absorbance immediately after photolysis (unliganded protein) and absorbance of CO-protein ("Initial Spectra") and between absorbance of Ngb-H64Q-CCC $100 \mu$ s, or Hb $1200 \mu$ s, after photolysis and that of CO-Ngb-H64Q-CCC or CO-Hb ("Final Spectra"). Note: Hb reaction is incomplete after $1000 \mu$ s. (F) Flash Photolysis: Kinetics (raw data and fits) of CO binding to the globins on a logarithmic scale, with $1 \mathrm{mM}$ of excess $\mathrm{CO}\left(\mathrm{k}_{\mathrm{Hb}}=4.62 \mathrm{~ms}^{-1} ; \mathrm{k}_{\mathrm{Ngb}-\mathrm{H} 64 \mathrm{Q}}=139 \mathrm{~ms}^{-1}\right.$;

$\left.\mathrm{k}_{\mathrm{Ngb}-\mathrm{H} 64 \mathrm{Q}-\mathrm{CCC}}=188 \mathrm{~ms}^{-1}\right)(\mathbf{G})$ Replacement by NO: Soret band of initial (CO-bound) and final (NO-bound) species for both $\mathrm{Hb}$ and Ngb-H64Q-CCC after the addition of $1 \mathrm{mM} \mathrm{NO}$ solution. (H) Replacement by NO: Kinetics (raw data and fits) of $\mathrm{CO}$ dissociation from $\mathrm{Hb}$ and Ngb-H64Q-CCC in presence of $1 \mathrm{mM}$ excess $\mathrm{NO}\left(\mathrm{k}_{\mathrm{Hb}}=7.65 \times 10^{-3} \mathrm{~s}^{-1} ; \mathrm{k}_{\mathrm{Ngb}-\mathrm{H} 64 \mathrm{Q}-\mathrm{CCC}}\right.$ $\left.=4.27 \times 10^{-4} \mathrm{~s}^{-1}\right)(\mathbf{I})$ The overall affinity was found to be $7.95 \pm 2.87 \times 10^{8} \mathrm{M}^{-1}$ for $\mathrm{Hb}$ and $2.54 \pm 1.13 \times 10^{11} \mathrm{M}^{-1}$ and $3.80 \pm 0.96 \times 10^{11} \mathrm{M}^{-1}$ for Ngb-H64Q and Ngb-H64Q-CCC, respectively. Error bars show SEM. All the experiments were repeated at least three times. 

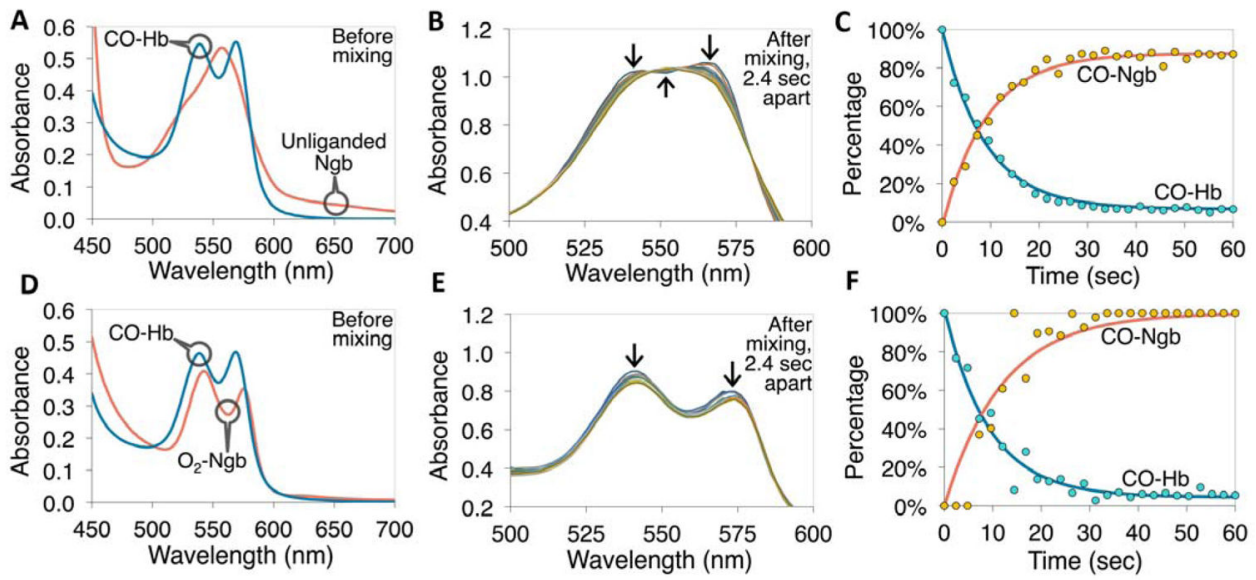

Fig. 2. CO transfer from free hemoglobin to Ngb-H64Q-CCC under anaerobic (A-C) and aerobic (D-F) conditions

(A) Example absorption spectra of $40 \mu \mathrm{M}$ CO-Hb and deoxy-Ngb-H64Q-CCC before mixing the two together at $37^{\circ} \mathrm{C}$, in presence of $5 \mathrm{mM}$ sodium dithionite. (B) Spectra measured every $2.4 \mathrm{~s}$ after mixing the two proteins together, arrows indicate the change in absorbance at specific wavelengths. (C) Kinetics (deconvoluted data and exponential fits) of the $\mathrm{CO}-\mathrm{Hb}$ and $\mathrm{CO}-\mathrm{Ngb}-\mathrm{H} 64 \mathrm{Q}-\mathrm{CCC}$ species. The measured reaction rate constant was 0.11 $\mathrm{s}^{-1}$ (half-life $6.4 \mathrm{~s}$ ). (D) Example absorption spectra of $33 \mu \mathrm{M}$ CO-Hb and $30 \mu \mathrm{M}$ oxy-NgbH64Q-CCC before mixing the two together at $37^{\circ} \mathrm{C}$, in presence of atmospheric oxygen.

(E) Spectra measured every $2.4 \mathrm{~s}$ after mixing the two proteins together; arrows indicate the change in absorbance at specific wavelengths. (F) Kinetics (deconvoluted data and exponential fits) of the $\mathrm{CO}-\mathrm{Hb}$ and $\mathrm{CO}-\mathrm{Ngb}-\mathrm{H} 64 \mathrm{Q}-\mathrm{CCC}$ species under aerobic conditions. The measured rate constant was $0.11 \mathrm{~s}^{-1}$ (half-life $6.4 \mathrm{~s}$, equal to example in the absence of oxygen). Reference spectra are shown in Fig. S5. All the experiments were repeated at least three times. 

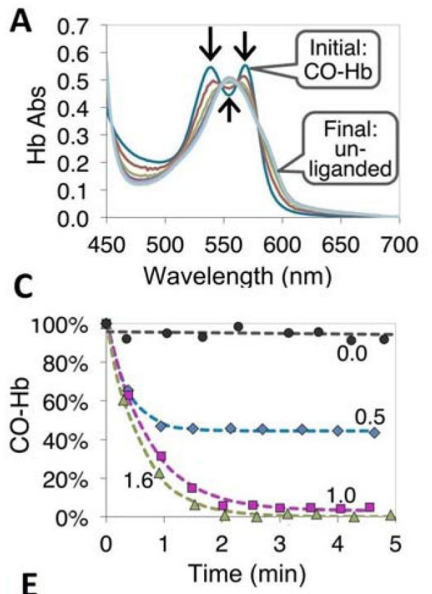

E
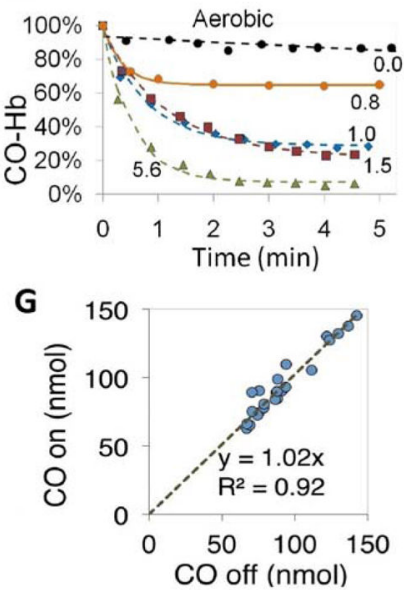

B
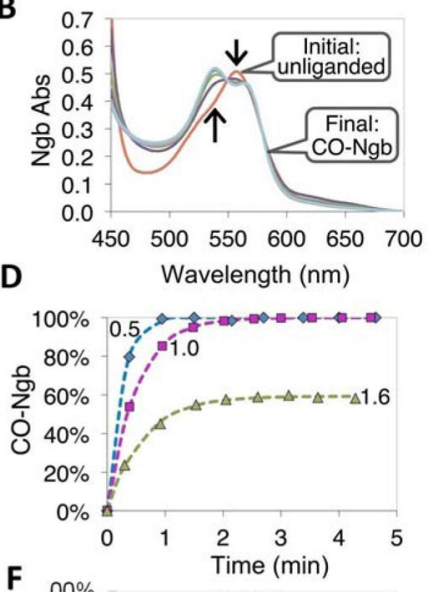

F

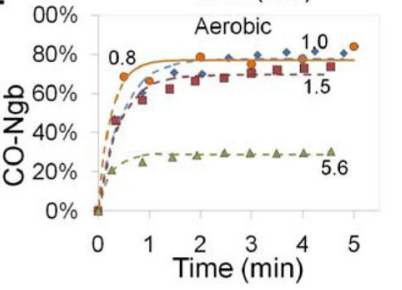

H

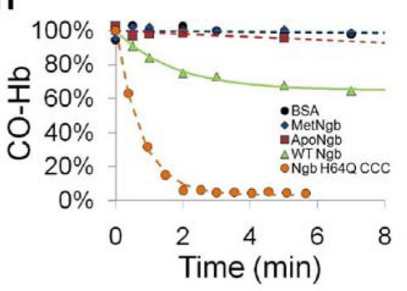

I

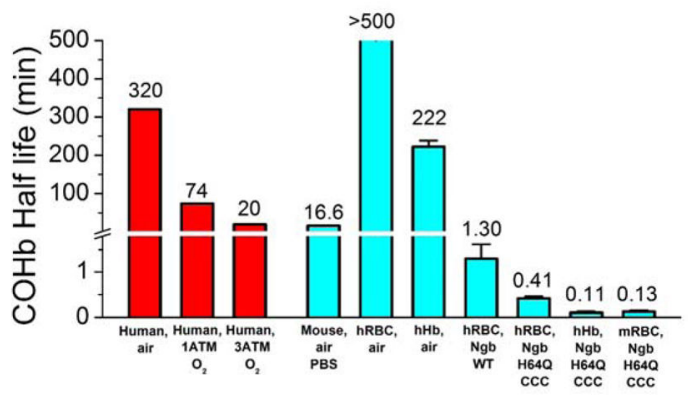

Fig. 3. CO transfer from RBC-encapsulated hemoglobin to Ngb-H64Q-CCC

(A - B) Absorbance spectra of $40 \mu \mathrm{M} \mathrm{Hb}$ and $40 \mu \mathrm{M}$ Ngb-H64Q-CCC, respectively, after mixing $\mathrm{CO}-\mathrm{Hb}$ with deoxy-Ngb-H64Q-CCC at $37{ }^{\circ} \mathrm{C}$ in presence of $10 \mathrm{mM}$ sodium dithionite. Arrows indicate the direction of absorbance changes. Initial spectra were recorded before mixing. (C - D) Time course of CO-Hb (C) and CO--Ngb-H64Q-CCC (D) concentrations after mixing at $37{ }^{\circ} \mathrm{C}$, in the presence of $3-10 \mathrm{mM}$ sodium dithionite. Numbers indicate the ratio of Ngb-H64Q-CCC to $\mathrm{Hb}$. The time courses for equimolar amounts of $\mathrm{Hb}$ and $\mathrm{Ngb}$ were derived from the spectra shown in (A) and (B) respectively. (E - F). Time course of CO-Hb (E) and CO--Ngb-H64Q-CCC (F) under aerobic conditions at $37{ }^{\circ} \mathrm{C}$. (G) The calculated moles of $\mathrm{CO}$ dissociated from $\mathrm{Hb}$ (x-axis) plotted against the calculated moles of CO bound to Ngb-H64Q-CCC, based on data in C - F, Fig. 2 and 
replicate experiments $(\mathrm{n}=29)$. $(\mathbf{H})$ Kinetic changes of RBC-encapsulated $\mathrm{CO}-\mathrm{Hb}$ when mixed with BSA, met-Ngb-H64Q-CCC, apo-Ngb-H64Q-CCC, wild type Ngb and deoxy Ngb-H64Q-CCC, Protein:Hb ratios used were 2 for BSA and 1 for met-Ngb, ApoNgb, WtNgb and deoxy Ngb-H64Q-CCC. (I) Half-lives of CO dissociation from RBCencapsulated or free $\mathrm{Hb}$ in mice and human. Human in vivo values were obtained from the literature $(1,34,36)$. Other values were measured in this work. Error bars show SEM. The experiments were repeated at least three times. 

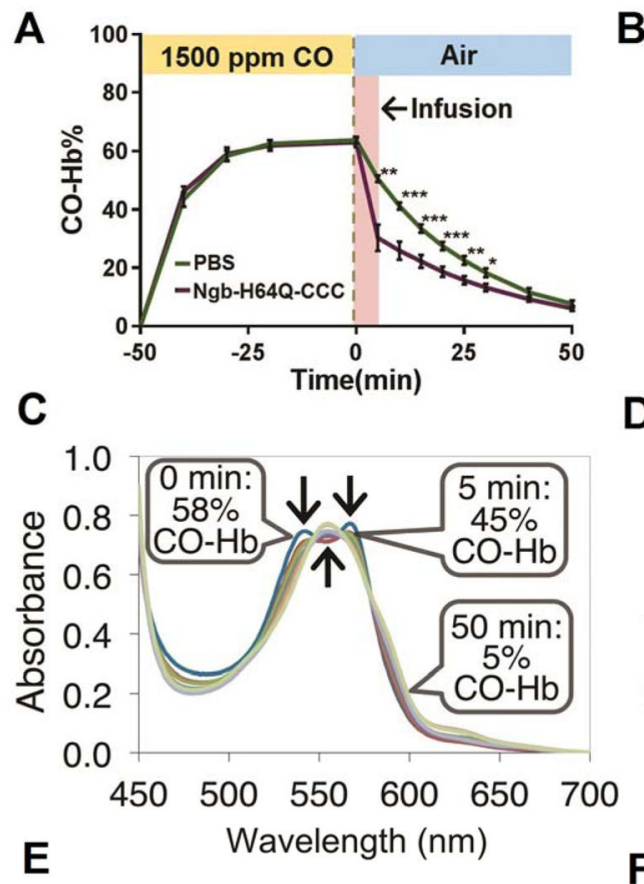

$\mathbf{E}$

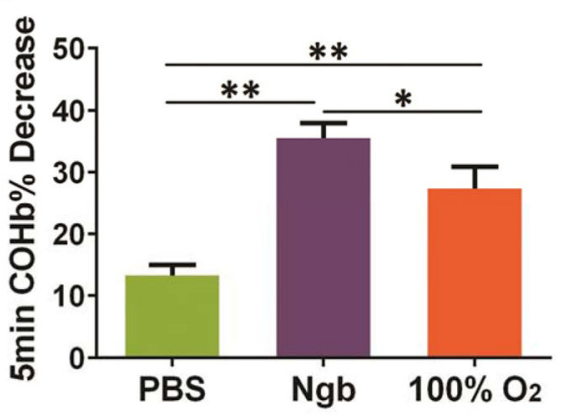

B
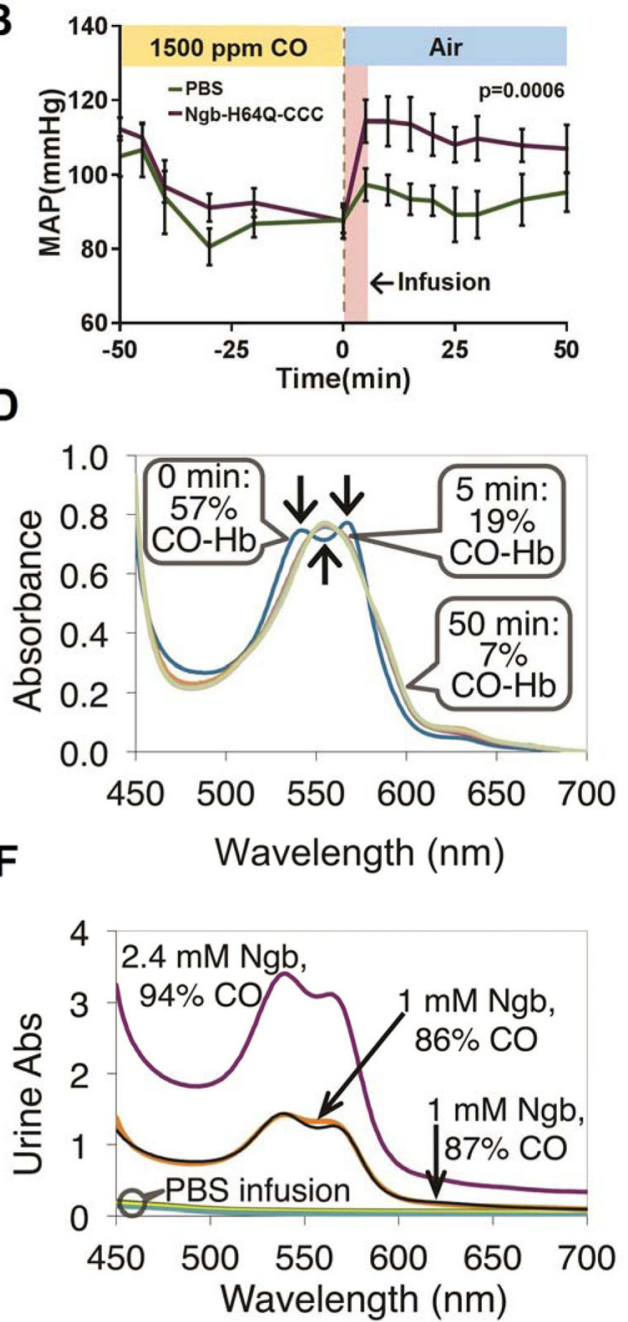

Fig. 4. In vivo CO transfer from RBC-encapsulated hemoglobin to Ngb-H64Q-CCC

(A - B) Time course of RBC-encapsulated CO-Hb (A) and mean arterial pressure (MAP)(B) before and after exposure of mice to $\mathrm{CO}$. Mice were exposed to $1500 \mathrm{ppm}$ of $\mathrm{CO}$ for 50 minutes; then ( $\mathrm{x}=0 \mathrm{~min}) \mathrm{CO}$ was turned off and animals returned to normal atmospheric conditions. At the same time, $250 \mu \mathrm{L}$ of either PBS or Ngb-H64Q-CCC (9-12 mM) were infused within 4 minutes. RBC-encapsulated $\mathrm{CO}-\mathrm{Hb}$ and MAP were periodically measured before and after treatment. Data are expressed as mean \pm SEM and $* P<0.05$, ** $P<0.01$, *** $P<0.005$ were calculated with the 2 -tail unequal variances Student's t-test. $P=0.0006$ for MAP for time $>0$, from mixed effect model with unstructured covariance. $(\mathbf{C}-\mathbf{D})$ Absorbance spectra of mouse $\mathrm{Hb}$ from representative experiments with PBS (C) or NgbH64Q-CCC infusion (D). The spectra correspond to the time points in (A)0 and (B). (E) Decrease in $\mathrm{CO}-\mathrm{Hb} \% 5$ minutes after end of $\mathrm{CO}$ exposure for mice that received PBS $(\mathrm{n}=$ $7)$, Ngb-H64Q-CCC $(\mathrm{n}=6)$ or $100 \%$ oxygen inhalation $(\mathrm{n}=5)$. Error bars show SEM. $P$ values were calculated by one way ANOVA. $* P<0.05$, $* * P<0.01$. (F) Absorbance of urine collected after the mice were sacrificed, 60 minutes after the end of $\mathrm{CO}$ exposure. Three mice that received Ngb-H64Q-CCC had a high $\mathrm{CO}-\mathrm{Ngb}$ urine content, while urine from the mice that received PBS did not contain heme proteins. 


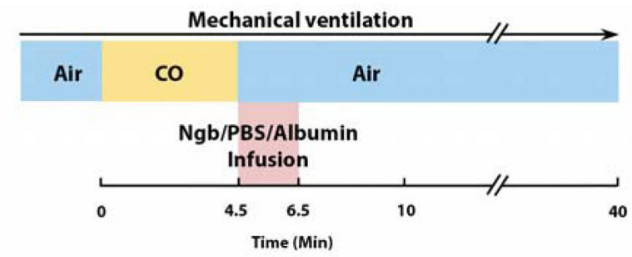

B

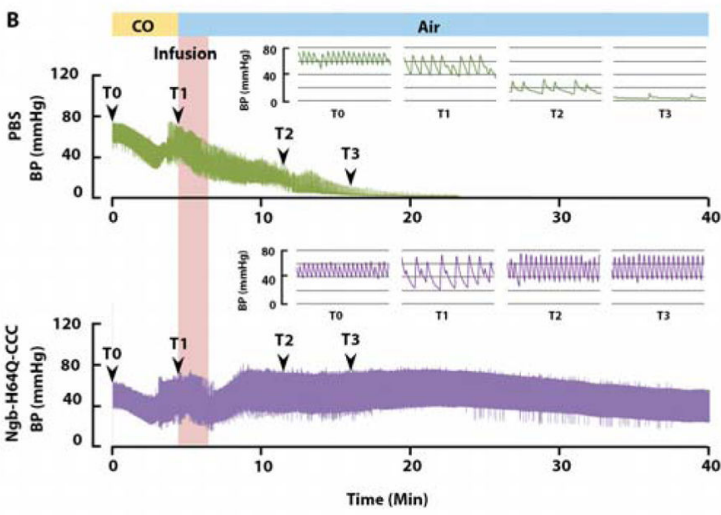

C

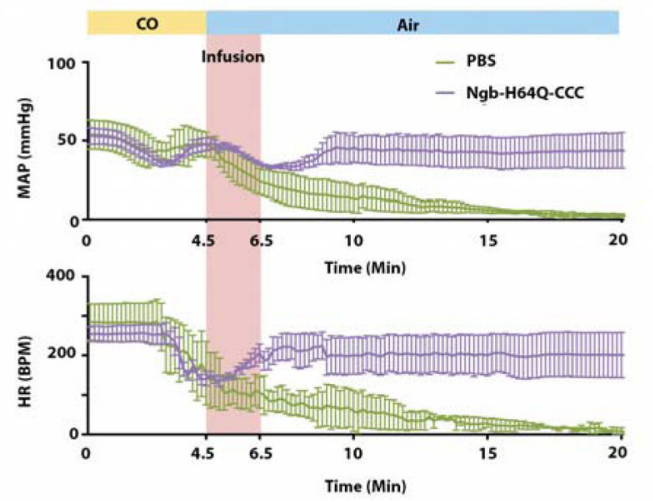

D
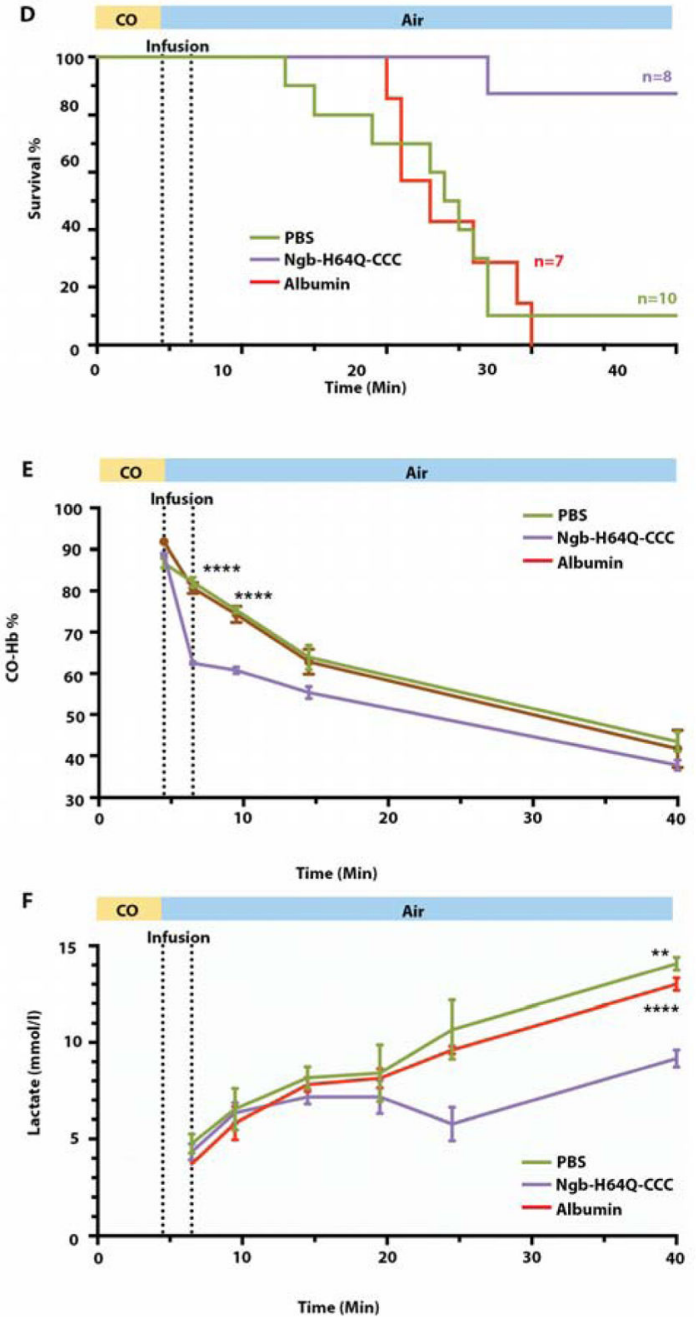

Fig. 5. Ngb-H64Q-CCC increases survival rate in a lethal CO poisoning model (A) Experimental scheme of the lethal $\mathrm{CO}$ poisoning model. Ventilation was initiated after the surgery with a volume controlled ventilator. 3\% CO mixed with air was delivered for 4.5 minutes via the ventilator. Air was delivered after stopping CO exposure and the Ngb-H64Q$\mathrm{CCC}$ or PBS/albumin control was infused within 2 minutes. All mice were followed for a pre-defined experimental observation period of 40-minutes. (B) Mean arterial blood pressure (MAP) and heart rate (HR) changes in mice treated with PBS and Ngb-H64Q-CCC. All data are expressed as means \pm SEM. (C) Representative MAP changes in one mouse treated with PBS and one Ngb-H64Q-CCC treated survivor. (D) Kaplan-Meier survival curves of mice exposed to $3 \% \mathrm{CO}$ for $4.5 \mathrm{~min}$ treated with PBS only $(n=10)$, albumin $5 \mathrm{mM}(\mathrm{n}=7)$ or NgbH64Q-CCC $(n=8)$ (Log-rank test survival, $P=0.0008)$. (E) Time course of RBCencapsulated CO-Hb with Ngb-H64Q-CCC $(n=3)$ vs. PBS $(n=4)$ and albumin $(n=4)$ in lethal CO poisoning model. Data are expressed as mean $\pm \mathrm{SEM}, P<0.0001$. (F) Lactate level elevation is lessened with Ngb-H64Q-CCC treatment $(n=3)$ vs. PBS $(n=4)$ and albumin $(n=4)$ in lethal $\mathrm{CO}$ poisoning. 

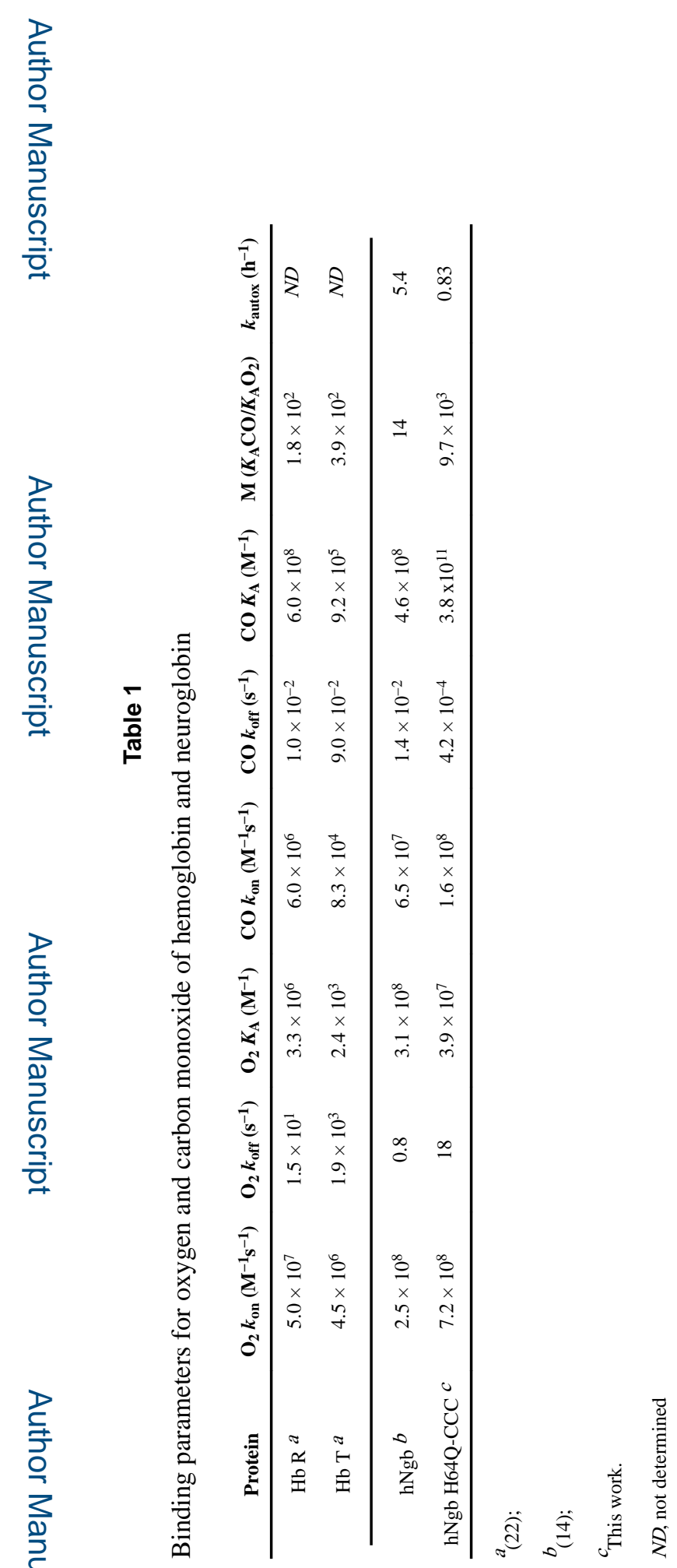

Sci Transl Med. Author manuscript; available in PMC 2017 June 07. 